\title{
Modelling the partitioning of ammonium nitrate in the convective boundary layer
}

\author{
J. M. J. Aan de Brugh ${ }^{1,2}$, J. S. Henzing ${ }^{2}$, M. Schaap ${ }^{2}$, W. T. Morgan ${ }^{3}$, C. C. van Heerwaarden ${ }^{4}$, E. P. Weijers ${ }^{5}$, \\ H. Coe ${ }^{3}$, and M. C. Krol ${ }^{1,6}$ \\ ${ }^{1}$ Meteorology and Air Quality Section, Wageningen University, Wageningen, The Netherlands \\ ${ }^{2}$ TNO, Earth, Environment and Life Sciences, Research Group Climate, Air and Sustainability, Utrecht, The Netherlands \\ ${ }^{3}$ Centre for Atmospheric Science, University of Manchester, Manchester, UK \\ ${ }^{4}$ Max Planck Institute for Meteorology, Hamburg, Germany \\ ${ }^{5}$ Energy research Centre of the Netherlands (ECN), P.O. Box 1, 1755 LE Petten, The Netherlands \\ ${ }^{6}$ Institute for Marine and Atmospheric Research Utrecht, The Netherlands
}

Correspondence to: J. M. J. Aan de Brugh (joost.aandebrugh@wur.nl)

Received: 7 October 2011 - Published in Atmos. Chem. Phys. Discuss.: 20 October 2011

Revised: 6 March 2012 - Accepted: 19 March 2012 - Published: 27 March 2012

\begin{abstract}
An explanatory model study is presented on semivolatile secondary inorganic aerosols on three clear days in May 2008 during the IMPACT campaign at the Cabauw tower in the Netherlands. A single column model in combination with the equilibrium aerosol model ISORROPIA is used. This model uses surface observations from IMPACT and calculates the gas-aerosol partitioning of ammonium nitrate. The calculated gas-aerosol equilibrium overestimates the gas phase fraction during daytime, and overestimates the aerosol phase fraction during night-time. This discrepancy can partly be solved when the approach of the gas-aerosol equilibrium is forced to proceed with a delay timescale of up to two hours. Although it is shown that the delay itself has a small effect, the most important effect is caused by the mixing of air from higher altitudes at which the equilibrium is shifted to the aerosol phase. Thus, vertical mixing is shown to have a significant influence on the calculated partitioning at the surface. On some occasions, the correspondence to the observed partitioning improves dramatically.
\end{abstract}

Even though gas-aerosol partitioning of ammonium nitrate is not instantaneous, observations show that a different equilibrium in the upper boundary layer causes aerosol ammonium nitrate concentrations to increase with altitude. Our model calculates similar vertical gradients depending on the assumed speed of gas-aerosol equilibrium. The calculated optical properties of the aerosol show a similar behaviour. The aerosol optical properties depend on the aerosol size distribution both directly, because light scattering de- pends on particle size, and indirectly, because the equilibration timescale depends on the aerosol sizes. Future studies should therefore focus on a fully size-resolved treatment of the gas-aerosol partitioning.

Finally, coarser-resolution models may treat the gasaerosol equilibrium of ammonium nitrate by calculating the equilibrium with a temperature and humidity sampled at a different altitude. We found that the equilibrium at an altitude of $200 \mathrm{~m}$ (night) up to $600 \mathrm{~m}$ (day) is representative for the partitioning of ammonium nitrate at the surface in the beginning of May 2008.

\section{Introduction}

Aerosols have a pronounced influence on the climate system, both directly by scattering and absorbing incoming solar radiation (Hess et al., 1998; Haywood and Boucher, 2000; IPCC, 2007) and indirectly by altering cloud properties (Rosenfeld et al., 2008; Kaufman et al., 2002). The combined climate effect of aerosols is poorly understood compared to the climate effect of greenhouse gases. In the Netherlands, nearly half $(42 \%-48 \%)$ of the fine aerosol $\left(\mathrm{PM}_{2.5}\right)$ mass consists of secondary inorganic aerosols (ammonium nitrate and ammonium sulphate) (Weijers et al., 2011), which are the dominant anthropogenic aerosol species in the size range with maximum light scattering $(0.4-1.0 \mu \mathrm{m})$ (ten Brink et al., 1997). Also, these secondary inorganic aerosols are effective 
cloud condensation nuclei, because of their size and water solubility. Due to intensive agriculture, the ammonia concentrations in the Netherlands have always been sufficiently high to neutralise sulphuric and nitric acid. During the last twenty-five years, sulphur dioxide emissions have decreased much more than those of nitrogen oxides in Europe and especially in the Netherlands (Vestreng et al., 2007, 2009). Therefore, ammonium nitrate has become increasingly important in comparison to ammonium sulphate. Ammonium nitrate and ammonium sulphate behave differently with varying temperature and relative humidity. First, ammonium sulphate resides exclusively in the aerosol phase, while ammonium nitrate resides in both the gas and the aerosol phase, where the gas-aerosol equilibrium strongly depends on the temperature and relative humidity. Furthermore, the aerosol water uptake by ammonium nitrate aerosol depends more strongly on the relative humidity than the water uptake of ammonium sulphate (Tang, 1996). Because both the aerosol dry mass (ammonium nitrate) and the aerosol water content is strongly enhanced at lower temperature and high relative humidity, the interaction of ammonium nitrate aerosol with solar radition is also more strongly increased at these conditions than that of ammonium sulphate aerosol. With ammonium nitrate becoming increasingly important, systematic investigation of these properties seems appropriate.

Research into ammonium nitrate partitioning is hampered by insufficient data availability. Most continuous measurements at ground-based stations are made with common filter packs and are prone to artefacts due to volatilisation of ammonium nitrate or absorption of nitric acid (Yu et al., 2006; Zhang and McMurry, 1992; Cheng and Tsai, 1997). Continuous measurements of total ammonium $\left(\mathrm{NH}_{3}+\mathrm{NH}_{4}^{+}\right)$and total nitrate $\left(\mathrm{HNO}_{3}+\mathrm{NO}_{3}^{-}\right)$are more widespread and therefore often used for validating large-scale models. Correct separation between aerosol and gas phase is only possible with denuders in combination with a filter pack or a Steam Jet Aerosol Collector (Slanina et al., 2001; Schaap et al., 2002; Trebs et al., 2004). For continuous measurements, these labour intensive are rarely used. Therefore, reliable measurements of aerosol ammonium nitrate are often campaignbased like EUCAARI-LONGREX (Kulmala et al., 2009) and the IMPACT-campaign at the Cabauw tower in the Netherlands (Morgan et al., 2010).

Correct representation of the partitioning of semi-volatile species has been a challenge for modellers as well. For partitioning of ammonium nitrate, many large-scale models use equilibrium models such as EQSAM (Metzger et al., 2002a,b) or ISORROPIA (Nenes et al., 1998; Fountoukis and Nenes, 2007). Large-scale models usually assume that the gas-aerosol system is always in equilibrium, which means that the timescale of gas-aerosol partitioning is assumed much shorter than that of other processes such as turbulent mixing of the convective boundary layer $(\sim 15 \mathrm{~min})$. Several studies, however, have pointed out that generally the gas-aerosol system is not in equilibrium (Wexler and Seinfeld, 1992; Meng and Seinfeld, 1996). Meng and Seinfeld (1996) pointed out that the timescale on which equilibrium is reached depends on the aerosol size and that the equilibrium assumption for coarse mode aerosols is generally not valid. Therefore, some studies use hybrid models, in which instant equilibrium is assumed for the fine fraction and a dynamic model is used for the coarse fractions (Capaldo et al., 2000; Feng and Penner, 2007).

Experimental evaluations of the equilibrium assumption for fine mode ammonium nitrate show contradicting results. A number of studies has shown that the predicted equilibrium is generally in accordance with observations (Zhang et al., 2003; Takahama et al., 2004; Yu et al., 2005). Others have shown that observations show generally larger particulate phase nitrate concentrations than predicted during summer and daytime (Moya et al., 2001; Fisseha et al., 2006; Morino et al., 2006). For the Netherlands, Schaap et al. (2011) compared ISORROPIA calculations with hourly observations of the gas-aerosol partitioning obtained with a MARGA system (Thomas et al., 2009). These authors modelled too abundant aerosol nitrate during the night and at daytime in winter as well as too abundant gaseous nitric acid during the day in summer. They attributed the mismatch to either an incorrectly calculated equilibrium or a non-instantaneous equilibrium.

It has been postulated that the relative abundant nitrate during daytime in summer may partly be due to transport of nitrate richer air from the upper parts of the boundary layer to the ground (Morino et al., 2006). With flight missions in the vicinity of the Cabauw tower (the Netherlands), Morgan et al. (2010) observed that air from the upper boundary layer is indeed richer in aerosol nitrate compared to the surface. Also, they tried to explain the observed scattering coefficients in the upper boundary layer from surface observations in combination with observed humidity-dependence of aerosol light scattering, assuming a well-mixed boundary layer. The observed scattering coefficients in the upper boundary layer were higher than the predictions up to a factor two, which was attributed to enhanced partitioning of semi-volatile gas phase species to the particulate phase in the upper convective boundary layer where lower temperatures and higher relative humidities prevail. In this paper, we test the hypothesis that ammonium and nitrate gas-aerosol partitioning is in non-instantaneous equilibrium and that vertical mixing may explain the mismatch between predicted and observed partitioning.

The main part of this article is a model study on the partitioning of ammonium nitrate. The model is explained in Sect. 2. We will reproduce the results of Schaap et al. (2011) with an ISORROPIA box model in Sect. 3.1. In Sect. 3.2, the column model results are presented. There, we will analyse the partitioning timescale by analysing the gas-aerosol partitioning at the surface, the vertical profiles of aerosol nitrate and the optical properties. Inspired by the model results, 
some technical analysis is done. In Sect. 3.3, we test the assumptions on which our optical calculations are based (see also Sect. 2.2.3). In Sect. 3.4, we provide a solution for coarse-resolution models for the issue that one cannot assume instant equilibrium of ammonium nitrate in the convective boundary layer.

\section{Materials and methods}

In this section, we describe the observations and the model used in this study as well as their interaction. Our study is based on observations collected at the Cabauw tower in the Netherlands $\left(51^{\circ} 58.223^{\prime} \mathrm{N}, 4^{\circ} 55.575^{\prime} \mathrm{E}\right)$ during the EUCAARI intensive measurement campaign (IMPACT). Our analysis focuses on May 2008, as the fair-weather conditions during this month are easier to simulate and because aircraft data were available. Below, we start with an overview of the meteorological, chemical and physical measurements. Next, the Wageningen University Single Column Model (WUSCM) is introduced.

\subsection{Observations}

The Cabauw Experimental Site for Atmospheric Research (CESAR; http://www.cesar-observatory.nl; Russchenberg et al., 2005) provides a host of meteorological data. We use primarily the temperature and the dew point temperature at $2 \mathrm{~m}$. From these quantities, the relative humidity is calculated. Furthermore, a CT75 Ceilometer provides aerosol backscatter profiles and therewith a qualitative indication of the boundary layer height. We will tune our model such that these observations are reproduced. Tuning parameters that influence the meteorology are initial temperature profiles, initial moisture profiles and a radiation tuning parameter that will be explained in Sect. 2.2.1. On clear days, this procedure leads to an excellent representation of the two-metre temperature and relative humidity (see Sect. 3.2.1). Furthermore, our modelled boundary layer height in the afternoon corresponds well with the ceilometer backscatter data.

We used hourly integrated data of both inorganic aerosol composition and the precursor gas concentrations as obtained with a MARGA-instrument (Schaap et al., 2011). MARGA (Monitor for AeRosols and Gases, Applikon Analytical BV) is the commercialised version of the GRAEGOR system (Thomas et al., 2009; ten Brink et al., 2009). Among other inorganic components, the gases $\mathrm{NH}_{3}$ and $\mathrm{HNO}_{3}$ as well as the $\mathrm{PM}$ components $\mathrm{NO}_{3}^{-}, \mathrm{SO}_{4}^{2-}$ and $\mathrm{NH}_{4}^{+}$were measured with hourly frequency. The sampling part of MARGA comprises a wet rotating annular denuder (WAD) for the collection of the precursor gases (Keuken et al., 1988) and subsequently a steam jet aerosol collector (SJAC) for the collection of the particulate matter (Khlystov et al., 1995; Slanina et al., 2001). The MARGA was located indoor while a Teflon coated $\mathrm{PM}_{10}$ (URG) inlet was mounted on the edge of the roof. For a more detailed description of the campaign and the instrument, we refer above-mentioned references (Schaap et al., 2011; Thomas et al., 2009; ten Brink et al., 2009; Keuken et al., 1988; Khlystov et al., 1995; Slanina et al., 2001). The concentrations of sulphate, total ammonium $\left(\mathrm{NH}_{3}+\mathrm{NH}_{4}^{+}\right)$and total nitrate $\left(\mathrm{HNO}_{3}+\mathrm{NO}_{3}^{-}\right)$are used to prescribe the model. The observed partitioning of ammonium nitrate is used to evaluate the model.

The aerosol size distribution is measured with a Scanning Mobility Particle Sizer (SMPS; Zieger et al., 2011; ten Brink et al., 1983; Wang and Flagan, 1990). The mobility size spectrometer consists of a sequential set-up of an impactor, neutraliser, differential mobility analyser (DMA) and a condensation particle counter (CPC). In the DMA, aerosol particles are classified according to their electrical mobility. The analyser consists of a cylinder with a negatively charged rod at the centre. Only aerosols in a narrow range of mobility exit through the output slit, where they enter the CPC, which determines the particle concentration of that size. The size of the particles reaching the output slit is being determined by the control rod voltage and the flow within the DMA. Before entering the DMA, aerosols are brought to a bipolar charge equilibrium using a ${ }^{85} \mathrm{Kr}$ bipolar charger (neutraliser). In charge equilibrium, the fraction of particles with a single emenentary charge is known for all sizes (Wiedensohler, 1988). Particles with diameter larger than about $800 \mathrm{~nm}$ are removed by a 0.0457 centimetre-diameter-orifice aerosol inlet in order to facilitate multiple charge correction. Because the aerosols are in charge equilibrium, the total number of particles can be calculated. The output data of the SMPS is a particles number size distribution as $\left(\frac{d N}{d \log D}\right)$, where $N$ is the number of aerosols and $D$ is the aerodynamic diameter. The SMPS at Cabauw measures 70 logarithmically equidistant size bins ranging from $10 \mathrm{~nm}$ to $520 \mathrm{~nm}$. The aerosol size distribution is only used for the optical module (see Sect. 2.2.3).

Morgan et al. (2010) present aircraft observations of 8 May and 21 May in the vicinity of Cabauw. Particulate sulphate, nitrate, ammonium and organics were observed during the flights at different altitudes with an on-board Aerodyne compact time-of-flight aerosol mass spectrometer (cToF-AMS) (Drewnick et al., 2005; Canagaratna et al., 2007). The AMS measures the fine fraction of the aerosol, with $100 \%$ transmission for aerodynamic diameters of 40-700 nm (DeCarlo et al., 2004). The scattering coefficient is measured with a TSI 3563 nephelometer (Anderson et al., 1996) at wavelengths of $450 \mathrm{~nm}, 550 \mathrm{~nm}$ and $700 \mathrm{~nm}$, of which the value at $550 \mathrm{~nm}$ wavelength is used in our analysis. The humidity dependence of the light scattering by the aerosols was obtained by measuring the scattering coefficient of a sample of aerosols at varying relative humidity $(\mathrm{RH})$ values, while keeping all other parameters fixed. The measured $\mathrm{RH}-$ dependency was fit with the following formula which is referred to as $f(\mathrm{RH})$ (Morgan et al., 2010).

$\sigma=\sigma_{\mathrm{dry}}\left(1+a \mathrm{RH}^{b}\right)$ 
Here, $\mathrm{RH}$ is the relative humidity $(0-1), \sigma$ is the scattering cross section and $\sigma_{\text {dry }}$ is the scattering cross section at dehydrated conditions $(\mathrm{RH}<40 \%)$. The parameters $a$ and $b$ were determined to fit the observations. The values of $a$ and $b$ may depend on aerosol composition and aerosol size distribution, but they should not directly depend on temperature. The $f(\mathrm{RH})$ is measured multiple times during a flight. As a result, the values for $a$ and $b$ represent the average situation during the whole flight.

\subsection{The model}

The Wageningen University Single Column Model (WUSCM) simulates boundary layer meteorology (radiation, land-atmosphere interaction and mixing) and can support chemistry schemes. For this study, we adopted a simple chemistry scheme that only involves gas-aerosol partitioning. Only seven tracers are taken into account: ammonia $\left(\mathrm{NH}_{3}\right)$, ammonium $\left(\mathrm{NH}_{4}^{+}\right)$, nitric acid $\left(\mathrm{HNO}_{3}\right)$, nitrate $\left(\mathrm{NO}_{3}^{-}\right)$, sulphate $\left(\mathrm{SO}_{4}^{2-}\right)$, bisulphate $\left(\mathrm{HSO}_{4}^{-}\right)$and aerosol water $\left(\mathrm{H}_{2} \mathrm{O}\right)$. The optical module is not coupled directly to the WUSCM model. This module calculates the scattering coefficient from the model output, without feeding back to the model.

For simplicity, this study does not employ a size-resolved aerosols scheme. Sizes of aerosols are only used for optical calculations, for which we use the observed aerosol size distribution (see Sects. 2.1 and 2.2.3). Furthermore, the interaction between sulphate, ammonium and nitrate with other components is neglected. It should be noted that sea salt (sodium chloride) may displace nitric acid, becoming sodium nitrate and outgassing hydrochlorid acid (Schaap et al., 2004; von Glasgow, 2008), shifting the partitioning of nitrate towards the aerosol phase. However, the simulated days were dominated by easterly winds and therefore low sea salt concentrations. Additionally, soluble organic matter may also influence the activity of inorganic components by uptake of additional water. These effects are difficult to represent in our model and are considered beyond the scope of this study.

The model has a resolution of 200 levels with equal pressure intervals of $150 \mathrm{~Pa}$, ranging from the surface to about three kilometres altitude and the soil is represented with four layers. No upper boundary condition is applied. In all our cases, the top of the domain $(\sim 3 \mathrm{~km})$ is far above the boundary layer, so the upper boundary condition does not directly influence our study area (the boundary layer) on the timescale of one day. The surface boundary condition is determined by observations as explained in Sect. 2.1. We use a model spin-up of one day. The model integrates with a third order Runge-Kutta system (Wicker and Skamarock, 2002), which means that tendencies for the individual processes (e.g. diffusion and chemistry) are evaluated and added. The overall time step is $20 \mathrm{~s}$.

\subsubsection{Meteorological module}

The radiation scheme is based on the Tropospheric Ultraviolet and Visible radiation model (TUV; Madronich, 1987). With TUV, we calculated the incoming short-wave radiation as function of zenith angle. We apply this radiation with a tuning parameter that accounts for the optical depth of the atmosphere (e.g. clouds). The calculated aerosol light scattering does not feed back on the incoming short-wave radiation.

Evapotranspiration is parameterised by calculating the canopy resistance, which depends on e.g. leaf area index. This resistance is corrected for short-wave radiation (Jarvis, 1976). The soil temperature, which is important for the longwave radiation budget, is also calculated by the model's surface scheme.

Boundary layer diffusion is simulated with the MediumRange Forecast (MRF) scheme following Troen and Mahrt (1986) and Hong and Pan (1996). Diffusion tendencies are implicitly determined. It includes non-local momentum fluxes according to Noh et al. (2003). The local diffusivities are calculated with the local Richardson numbers and the counter-gradient fluxes are calculated with a constant for excess temperature.

\subsubsection{Chemical module}

Our model employs ISORROPIA version 2 (Fountoukis and Nenes, 2007) to calculate the gas-aerosol equilibrium. ISORROPIA calculates the fraction of aerosol phase ammonium and nitrate at equilibrium given the total ammonium $\left(\mathrm{NH}_{3}+\mathrm{NH}_{4}^{+}\right)$concentration, the total nitrate $\left(\mathrm{HNO}_{3}+\mathrm{NO}_{3}^{-}\right)$ concentration, the sulphate concentration, the temperature and the relative humidity. ISORROPIA also calculates the water content of the aerosols at equilibrium. ISORROPIA uses a bulk aerosol approach, so no aerosol size distribution is taken into account to calculate the gas-aerosol equilibrium. To mimic the fact that equilibrium is not reached instantaneously, we introduce a parameter, $\tau_{\mathrm{p}}$ to set the speed at which the equilibrium is reached. The tendency given by ISORROPIA to the model is

$$
\frac{d \boldsymbol{C}}{d t}=\frac{\boldsymbol{C}_{\mathrm{eq}}-\boldsymbol{C}}{\tau_{\mathrm{p}}}
$$

Here, $\boldsymbol{C}$ is the concentration vector of all tracers, and $\boldsymbol{C}_{\mathrm{eq}}$ is the equilibrium calculated by ISORROPIA. The parameter $\tau_{\mathrm{p}}$ will be used as a tuning parameter that we will vary to improve the correspondence to observations. If we want to assume instant equilibrium, we use $\tau_{\mathrm{p}}=20 \mathrm{~s}$, equal to the general time step to keep the model numerically stable.

In reality, aerosols may exhibit a phase hysteresis (Wang et al., 2008). Depending on the history of the relative humidity, aerosols may be in a metastable (supersaturated) state or in a solid state coated with saturated liquid material. In our study area (the Netherlands), the humidity is generally high 
enough (40\% and higher), so we assume that our aerosols remain at the humid, metastable side of the hysteresis.

The concentrations of the inert tracers: sulphate, total nitrate $\left(\mathrm{NO}_{3}^{-}+\mathrm{HNO}_{3}\right)$ and total ammonium $\left(\mathrm{NH}_{4}^{+}+\mathrm{NH}_{3}\right)$ at the surface were prescribed equal to the time-interpolated observations at Cabauw. This allows us to represent the correct concentrations of these tracers without implementation of processes like advection, emission and deposition. When updating a concentration, the partitioning between gas and aerosol phase is set equal to that of the previous time step in the model. Although this prescription works well, it should be realised that advection, emission or deposition of ammonium or nitrate with a different partitioning can cause biases, because the prescription leaves the partitioning the same. This can influence the results when the timescale of partitioning is large. Finally, prescription of the total-concentrations at the surface may result in slight biases when advection occurs in the upper convective boundary layer. Due to the strong vertical mixing during daytime, we think that these biases are generally small. In general, the above-described procedure works adequately for a well-mixed boundary layer. Our analysis will therefore focus on the daytime, which is also the most relevant for the radiative effect of aerosols.

\subsubsection{Optical module}

We model the light scattering by the aerosols with a Miescattering module (O. Boucher, personal communication, 2004). This code calculates the scattering cross section of aerosols with a certain size $\left(x=\frac{2 \pi r}{\lambda}\right)$ and complex refractive index $(m)$. We apply the Mie-calculation for 70 size bins with SMPS measurements as input.

The SMPS instrument measures the aerosol size distribution as a differential aerosol count in an aerodynamic diameter range $\left(\frac{d N}{d \log D_{\mathrm{a}}}\right)$. The optical calculations require the number concentrations $\left(\frac{N}{V}\right)$ per size bin. For the optical calculations, it is very important that the aerosol number concentration and size distribution are consistent with the total aerosol mass. Without calibration, the observed aerosol number concentration is not consistent with the modelled aerosol mass. For example, the model neglects organic aerosol mass, while organic aerosols are counted by the SMPS. Also, the model assumes spherical aerosols with volume equal to $\frac{\pi}{6} D_{\mathrm{a}}^{3}$. In reality, the mass of an aerosol with aerodynamic diameter $D_{\mathrm{a}}$ may be different. Therefore, the SMPS output has to be calibrated to match with the model assumptions. Thus a normalisation constant is required for the conversion.

$$
\frac{N}{V} \equiv S \frac{d N}{d \log D}
$$

This normalisation constant $S$ scales the measured $\frac{d N}{d \log D}$ to reproduce $\frac{N}{V}$ for all size bins in such a way that it fits with the modelled aerosol material. It is obtained by setting up an equation for the total aerosol volume per cubic metre air.
On the left hand side, we calculate the total aerosol volume by adding up the volume (mass divided by density) of the aerosol components. On the right hand side, we add up the aerosol numbers and calculate their volumes assuming a spherical shape.

$\sum_{j} \frac{C_{j, \text { surf }}}{\rho_{j}}=\frac{\pi}{6} S \sum_{i}\left(\frac{d N}{d \log D}\right)_{i} D_{i, \mathrm{SMPS}}^{3}$

On the left hand side, $j$ is an aerosol component (ammonium nitrate and ammonium sulphate), $\rho_{j}$ is the density of component $j$ and $C_{j \text {,surf }}$ is the modelled mass concentration of component $j$ at the surface. On the right hand side, $i$ is a size bin, $\left(\frac{d N}{d \log D}\right)_{i}$ is the measured quantity by the SMPS for bin $i$, and $D_{i \text {,SMPS }}$ is the size (diameter) of the size bin $i$. The label "SMPS" is added to indicate that this is the size of the aerosols when they are measured by the SMPS. The normalisation constant $S$ is then obtained as:

$S=\frac{6}{\pi} \frac{\sum_{j} \frac{C_{j, \text { surf }}}{\rho_{j}}}{\sum_{i}\left(\frac{d N}{d \log D}\right)_{i} D_{i, \mathrm{SMPS}}^{3}}$

Note that we do not include water in the aerosol components $j$, because the SMPS measures the size of the aerosols after drying. However, we include ammonium nitrate, although it may have evaporated from the aerosols on drying.

The aerosol number concentration is required over the entire vertical model domain, while the above-mentioned algorithm only calculates the aerosol number concentration at the surface. We assume that aerosol numbers are inert, which means that we assume that no nucleation or coagulation of particles takes place on vertical transport. Therefore, the vertical profile of the aerosol number concentrations should be similar to that of an inert tracer (e.g. total nitrate). To apply this vertical profile, we introduced an inert vertical normalisation tracer $(Z)$ that is fixed at unity at the surface and subject to vertical mixing. In general, $Z$ will be well-mixed $(Z=1)$ in the convective boundary layer and will have a sharp descending gradient in the transition to the free troposphere. Applying this vertical profile completes our definition of the number concentration per size bin.

$$
\frac{N_{i}}{V}(z)=Z(z) S\left(\frac{d N}{d \log D}\right)_{i}
$$

We calculate the refractive index of the aerosol with the modelled volume fractions of the aerosol tracers (including water) and the refractive indices of the materials. We assume a mixture of water, ammonium nitrate and ammonium sulphate with no clear dominant component (The modelled concentrations of ammonium bisulphate or not-neutralised ammonium or nitrate are negligible). The formula for the effective refractive index is as follows (Aspnes et al., 1979; Bruggeman, 1935).

$\sum_{j} p_{j} \frac{m_{j}^{2}-m_{\mathrm{eff}}^{2}}{m_{j}^{2}+2 m_{\mathrm{eff}}^{2}}=0$ 
Here, $m_{\text {eff }}$ is the effective refractive index, $p_{j}$ is the volume fraction of component $j$, and $m_{j}$ is the refractive index of component $j$. The effective refractive index is solved numerically.

Our model only includes ammonium nitrate $(m=1.6$; Weast, 1985), ammonium sulphate $(m=1.53$; Toon et al., $1976)$ and water ( $m=1.33$; Hecht, 2003). Therefore, $m_{\text {eff }}$ is not expected to vary considerably. Moreover, the effect of the refractive index is much smaller than the effect of an increase in geometrical cross section of the aerosols by hygroscopic growth. Therefore, we think that variations in the refractive indices only play a minor role.

The last thing required for the optical calculation is the actual size of the aerosols per bin (at any altitude). The actual size is generally larger than the dry size measured at the SMPS because of condensation of water and eventually additional ammonium nitrate. Our assumption of inert aerosol numbers (see above) implies that the number concentration does not change because of condensation of water and additional ammonium nitrate. The new size of the aerosols should be sufficient to fit all material (ammonium sulphate, ammonium nitrate and water):

$\sum_{j} \frac{C_{j}(z)}{\rho_{j}}=\frac{\pi}{6} Z(z) S \sum_{i}\left(\frac{d N}{d \log D}\right)_{i} D_{i, \text { actual }}^{3}(z)$

This equation differs from Eq. (4) in three aspects. First, the concentration of aerosol components and numbers are now at altitude $z$ instead of at the surface. Second, the diameter of the aerosols is now the actual (wet) diameter instead of the dry diameter and therefore water is also included in the components $j$. Third, the normalisation constant $S$ is now known (from Eqs. 4 and 5) while the diameters $\left(D_{i, \text { actual }}(z)\right)$ are unknown and should be solved. This single equation has 70 unknowns (one $D_{i \text {,actual }}(z)$ for size bin), so there is by far no unique solution. By choosing which solution of Eq. (8) to take, we will choose the way in which additional material is distributed over the size bins. We will introduce two possibilities to distribute the condensed material over the size bins.

One way is to assume mutual equilibrium between the aerosols. That is achieved by enforcing the same composition for each aerosol size class, which means that the volume of condensed matter should be proportional to the aerosol volume.

$$
\begin{array}{r}
d V \equiv X V=\frac{\pi}{6} X D^{3} \\
d V=\frac{\pi}{2} D^{2} d D \\
\frac{\pi}{2} D^{2} d D=\frac{\pi}{6} X D^{3} \\
d D=\frac{1}{3} X D
\end{array}
$$

Here, $X$ is defined as the constant of proportionality between the volume of the condensed matter $(d V)$ and the aerosol volume $(V)$. In this case, all aerosol diameters grow with a constant factor $\left(\frac{1}{3} X\right)$. This factor can be calculated with the following formula.

$\frac{D_{i, \text { actual }}}{D_{i, \text { SMPS }}}=\sqrt[3]{\frac{\sum_{j} \frac{C_{j}(z)}{\rho_{j}}}{\sum_{j} \frac{C_{j, \text { surf }}}{\rho_{j}}}}$

Note that aerosol water is not counted in the term $C_{j \text {,surf }}$, like in Eq. (5).

A second possibility that we will explore is the distribution of the condensable material proportional to aerosol surface, the area where condensation takes place.

$$
\begin{array}{r}
d V \equiv X A=\pi X D^{2} \\
d V=\frac{\pi}{2} D^{2} d D \\
\frac{\pi}{2} D^{2} d D=\pi X D^{2} \\
d D=2 X
\end{array}
$$

Here, $X$ is defined as the constant of proportionality between the volume of the condensed matter $(d V)$ and the aerosol surface area $(A)$. In this case, all diameters grow with a constant amount ( $2 X)$. The value of $d D$ can be solved by substituting $D_{i, \text { actual }}$ with $D_{i, \mathrm{SMPS}}+d D$ in Eq. (8) and solve $d D$ numerically.

$$
\sum_{j} \frac{C_{j}(z)}{\rho_{j}}=\frac{\pi}{6} Z(z) S \sum_{i}\left(\frac{d N}{d \log D}\right)_{i}\left(D_{i, \mathrm{SMPS}}+d D\right)^{3}
$$

On short timescales, aerosols will tend to grow proportional to surface area $\left(\sim D^{2}\right)$. If the ambient conditions remain constant for a longer time period, the different aerosol size classes have time to equilibrate. In such cases, the aerosols have grown proportional to volume $\left(\sim D^{3}\right)$. This change from $\left(\sim D^{2}\right)$ to $\left(\sim D^{3}\right)$ has been shown by Meng and Seinfeld (1996). They present a box-model simulation with two different aerosol size classes in disequilibrium with gas. Initially the fine aerosols equilibrate with the gas by quick condensation $\left(\sim D^{2}\right)$. Later on, the coarse aerosols equilibrate with the gas, depleting the gas phase concentrations. Then, the fine aerosols are no longer in equilibrium with the gas and the semi-volatile components evaporate out again $\left(\sim D^{3}\right)$. An illustrative example is given in Fig. 2 of Meng and Seinfeld (1996). It is hard to determine which of the two possibilities is best and the actual distribution is probably somewhere in between, depending on the rate of change of the ambient conditions. Since conditions of an air mass change fast in a convective boundary layer, our main result will be calculated with the $\left(\sim D^{2}\right)$-distribution. Sensitivity studies will show the difference when using the $\left(\sim D^{3}\right)$-distribution (Sect. 3.3).

With the number concentrations for each bin, the refractive index of the aerosols and the actual size of each bin, we can calculate the scattering coefficient with the Mie module. 


\section{Results and discussion}

First, we will calculate the equilibria of the gas-aerosol system with ISORROPIA and compare these to surface observations for a long measurement period. Next, we will present the calculated surface partitioning, aerosol nitrate profiles and scattering profiles, using the model as explained in Sect. 2 for three clear days in May 2008. We will compare these with surface and aircraft observations.

\subsection{ISORROPIA only}

In contrast to other countries, the ammonia concentration in the Netherlands is in most cases sufficiently high to neutralise all sulphate and all nitrate (Schaap et al., 2004). Excess ammonia remains in the gas phase regardless of the meteorological situation, resulting in a minimum gas phase fraction greater than $0 \%$ for ammonium (not shown). The nitrate partitioning, however, varies between $100 \%$ gas and $100 \%$ aerosol, making it a good indicator for the gas-aerosol equilibrium. Therefore, we will focus on the nitrate partitioning.

Schaap et al. (2011) already showed that ISORROPIA calculates a too large aerosol nitrate fraction during winter and during summer nights and a too large gas phase fraction during summer days. We reproduced these results. In Fig. 1, the results of just May 2008 are shown, which can be considered a summer month. The observed nitrate partitioning sometimes exhibits a clear diurnal cycle, for example in the period from 6 to 13 May (see Fig. 1). During this period with fair weather conditions with weak wind, the diurnal cycles in the calculated equilibria are too large and have a small phase shift, with the calculations an hour or two ahead of the observations. Because these periods are easier to represent in a simplified model, the focus of our study will be on three clear days. On some days, for instance 17 to 31 May, the diurnal cycle in the observations is disturbed. ISORROPIA sometimes calculates no diurnal cycle at all (e.g. 17 or 27 May), overestimating the aerosol phase fraction like in the winter. On many days, however, ISORROPIA exhibits a diurnal cycle, which is smaller than during the fair-weather period. There is no clear relationship between total nitrate concentration and the partitioning.

The three days selected for our study are displayed in Fig. 2. We recognise a diurnal cycle in the observed partitioning on 6 May. On 8 May, the observations start similar to 6 May, but the gas phase fraction suddenly decreases in the evening hours. On 21 May, both ISORROPIA and the observations show a large aerosol fraction, which is due to the relatively low temperature on that day. However, the observed partitioning lacks a clear diurnal cycle, while ISORROPIA still shows a diurnal cycle like the other days. Our hypothesis is that the gas-aerosol system does never reach equilibrium. This may explain differences between the ISORROPIA calculations and the observations, even if the equilibrium calculated by ISORROPIA is correct. With a non-instantaneous equilibrium, turbulent mixing of air from higher altitudes influences the partitioning at the surface.

\subsection{Column model results}

We performed three simulations for each of the three selected days, in which we set the partitioning timescale parameter $\left(\tau_{\mathrm{p}}\right)$ to $20 \mathrm{~s}, 1800 \mathrm{~s}$ and $7200 \mathrm{~s}$ (see Eq. 2). The 20 -s timescale mimics instant equilibrium. With these simulations, we test the hypothesis that a non-instantaneous equilibrium bridges the gap between the calculated equilibrium by ISORROPIA and the observed partitioning (see Figs. 1 and 2).

\subsubsection{Tuning the meteorology}

As we explained in Sect. 2.1, we tune meteorological input data to reproduce the CESAR data. In Fig. 3 is shown that the temperature is represented very well and the relative humidity is represented reasonably. The root of the mean square error in the temperature is $0.44,0.77$ and $0.54{ }^{\circ} \mathrm{C}$ for 6,8 and 21 May respectively and during the afternoon hours (the period of interest, 12:00-18:00 UTC) only 0.18, 0.21 and $0.34{ }^{\circ} \mathrm{C}$. The root of the mean square error in the relative humidity is $7.5,7.8$ and 6.2 percent $(3.4,4.7$ and 2.6 percent during afternoon) for 6,8 and 21 May, respectively.

We underestimate the humidity in the morning by $10-14 \%$ and we overestimate the humidity in the evening by an equal amount. This is probably caused by a too sharp increase and decrease of the boundary layer height during the morning and evening transitions in the model. This means that we model too much dry air entrainment in the morning, reducing the humidity. In the evening, we model a too shallow boundary layer $(\sim 30 \mathrm{~m})$, where moist air is trapped, increasing the humidity. The nocturnal boundary layer height at Cabauw usually ranges from $60 \mathrm{~m}$ to $540 \mathrm{~m}$ and is often underestimated by models (Steeneveld et al., 2007). The boundary layer height reaches its maximum close to $2 \mathrm{~km}$ for 8 and 21 May and about $1.5 \mathrm{~km}$ for 6 May. With the aid of the provided backscatter data, we estimate that the mismatch with the real boundary layer heights is in the order of a hundred metres.

\subsubsection{Partitioning at the surface}

To illustrate the effect of a delayed equilibrium, we first show ISORROPIA calculations with a partitioning timescale taken into account and applying Eq. (2), but not taking into account boundary layer mixing. For these calculations, we used timeinterpolated meteorological data from the CESAR observations and time-interpolated observations of total ammonium, total nitrate and sulphate from the MARGA. This results in a very small weakening and delay of the diurnal cycle on increasing $\tau_{\mathrm{p}}$ (see Fig. 4). Secondly, we show modelled surface partitioning of nitrate in our column model with the meteorological situation tuned as in Sect. 3.2.1. This results in a much greater weakening and delay of the diurnal cycle 


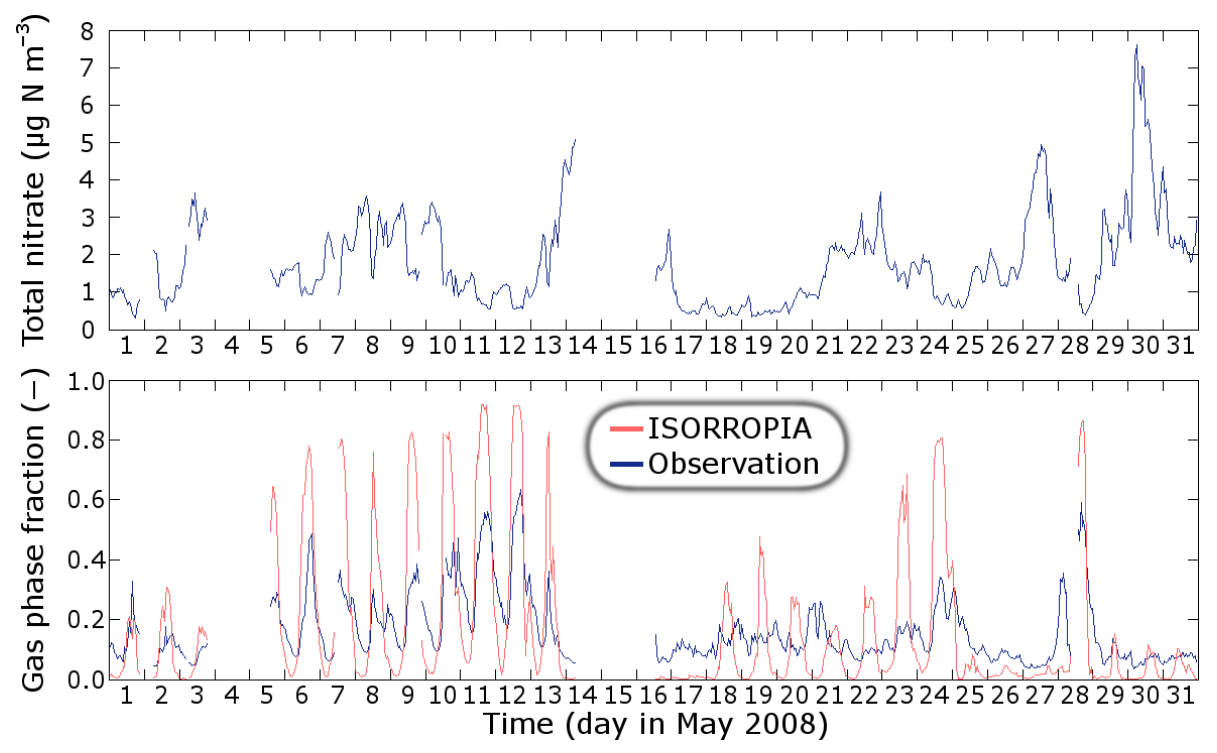

Fig. 1. Upper panel: observed total nitrate (nitric acid plus aerosol nitrate) concentration at Cabauw for May 2008. Lower panel: observed partitioning of nitrate and equilibrium by ISORROPIA for May 2008. Gaps in the graphs are caused by missing data.

as well as an average shift towards the aerosol phase (see Fig. 5). Additionally, small differences occur because the column model uses tuned meteorology (Sect. 3.2.1), while the (nudged) ISORROPIA equilibrium use direct CESAR data. These latter differences are the only differences visible in the simulation with quasi-instantaneous equilibrium $\left(\tau_{\mathrm{p}}=20 \mathrm{~s}\right)$.

The greater weakening and delay of the diurnal cycle as well as the shift towards the aerosols phase in the column model (Fig. 5) are caused by vertical mixing. In the convective boundary layer, air from the upper boundary layer is mixed towards the surface. That air experienced a lower absolute temperature and a higher relative humidity and thus contains more aerosol nitrate and less nitric acid compared to the equilibrium at the surface. If the equilibrium is restored only slowly (high $\tau_{\mathrm{p}}$ ), the nitrate remains longer in the aerosol phase, resulting in a higher aerosol fraction of nitrate at the surface. This effect causes a further weakening of the diurnal cycle. Moreover, because there is no counterbalancing effect during the night (mixing through the nocturnal boundary layer is inefficient), this effect also displaces the average towards the aerosol phase. Furthermore, the enhancement of aerosol nitrate in the convective boundary layer causes the maximum gas phase fraction to occur after the convective boundary layer has collapsed (18:00 UTC or later, see Fig. 5), indicating that convective mixing has a significant effect on the nitrate partitioning at the surface.

Increasing the timescale of partitioning improves the correspondence of the modelled nitrate partitioning at the surface to the observations, especially on days where advection plays no significant role, which is indicated by a smooth diurnal cycle in the observed surface nitrate partitioning (e.g.
6 and 11 May). The improvement on 6 May with $\tau_{\mathrm{p}}=7200 \mathrm{~s}$ is impressive (compared to ISRROPIA-only, the root mean square error is reduced by factor 2.1 over the entire day and by 5.9 over the afternoon hours: 12:00-18:00 UTC, see Fig. 5). On 8 and 21 May, we model too low gas phase fractions during the night. Our model, specialised in the convective boundary layer, evidently has more difficulties during the night. Also, the diurnal cycles in the observed partitioning on 8 May and 21 May are disturbed, very likely by advection. Our model, not able to simulate advection, will always result in a smooth diurnal cycle. On 8 May, we model the correct maximum gas phase fraction (30\%) with $\tau_{\mathrm{p}}=7200 \mathrm{~s}$, which is an improvement over the instant-equilibrium simulation. However, the timing of the peak is better with shorter $\tau_{\mathrm{p}}$. On 21 May, we model approximately the correct gas phase fraction in the afternoon (10\%), with a smaller $\tau_{\mathrm{p}}$-sensitivity. This low gas phase fraction is caused by the low temperature on that day. It should be considered that there may be a systematic overestimation of the nitrate gas phase fraction in our model, because the model does not take the interaction with sea salt into account (where chloride is displaced by nitrate, see Sect. 2.2). Though it is difficult to quantify this effect, this might suggest that a timescale of 1800 s produces good results on 6 May with a well-timed maximum gas phase fraction around 18:00 UTC that is overestimated by $17 \%$.

\subsubsection{Aerosol nitrate profiles}

The diurnal variation of the modelled aerosol nitrate profiles are displayed in Fig. 6. Several afternoon profiles show enhanced aerosol nitrate concentrations with altitude within the well-mixed boundary layer due to different gas-aerosol equilibria in the lower and upper boundary layer. The longer the 

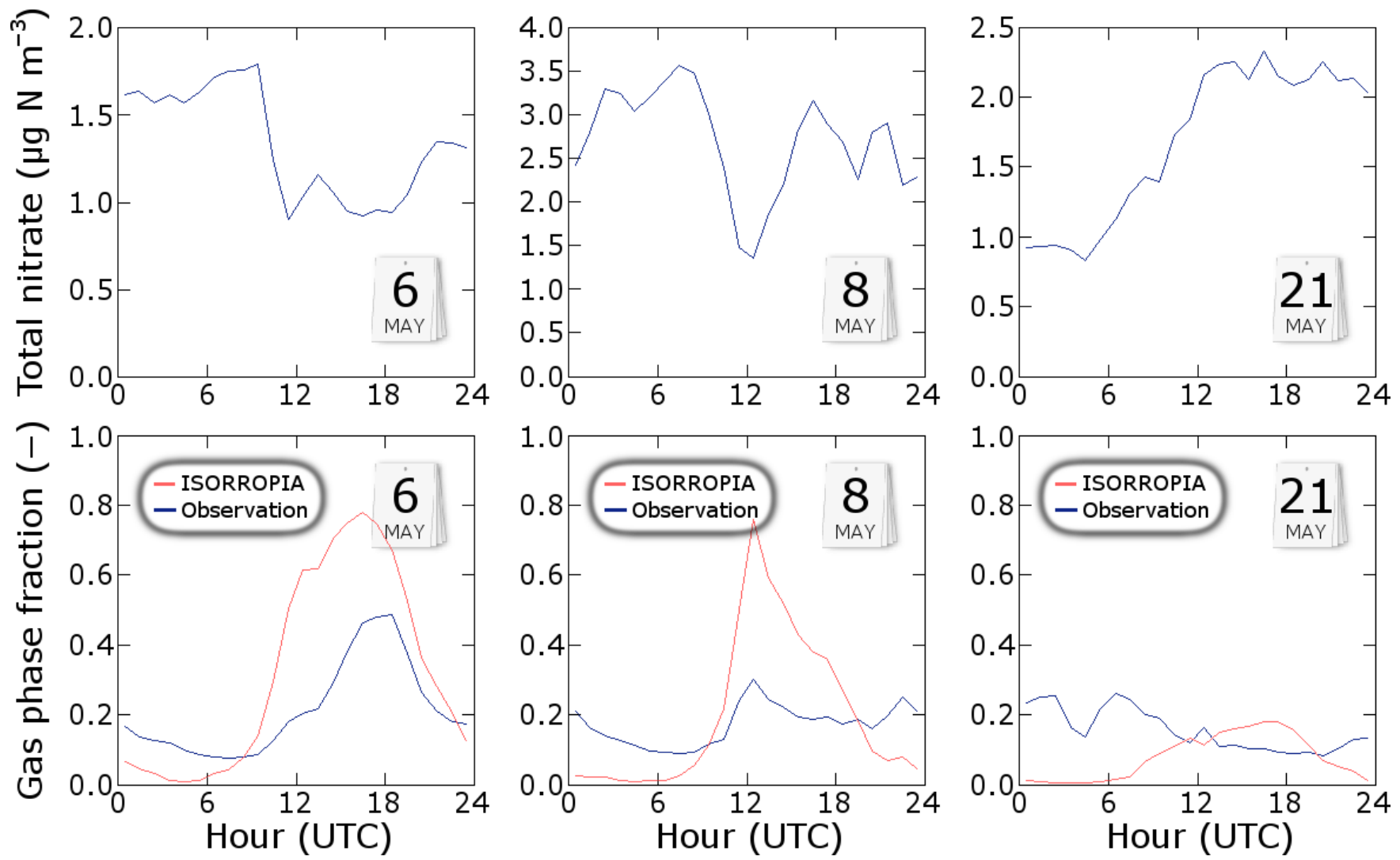

Fig. 2. Upper panels: observed total nitrate (nitric acid plus aerosol nitrate) concentration at Cabauw for 6 May (left), 8 May (middle) and 21 May (right). Lower panels: observed partitioning of nitrate and equilibrium by ISORROPIA for these days.

partitioning timescale, the weaker the vertical nitrate gradients, because vertical mixing plays a more prominent role at high $\tau_{\mathrm{p}}$. The strength of the vertical gradient is positively correlated with the gas phase fraction of nitrate at the surface, which is largest on 6 May and smallest on 21 May. This is logical, because the conditions favour the aerosol phase at higher altitude. Therefore, it is the gas phase nitric acid at the surface that may undergo a phase transition when moving to the upper boundary layer.

In Fig. 7, the modelled aerosol nitrate profiles are compared to aircraft observations presented in Morgan et al. (2010) (shown in Fig. 6 therein for 8 May). For the comparison, the aircraft data were converted in two aspects. First, the masses $\mathrm{NO}_{3}^{-}$were converted to masses $\mathrm{N}$ (scales down a factor 4.4). Second, the scaling to standard temperature and pressure, which is done in Morgan et al. (2010), was undone. The latter conversion reduces the concentrations in the upper boundary layer. To visualise this effect, the dashed reference line is shown. This line corresponds to a fixed scaled concentration of $2.0 \mu \mathrm{g} \mathrm{N} \mathrm{sm}^{-3}$. The modelled profiles in Fig. 7 are from 15:30 UTC for 8 May and from 11:30 UTC for 21 May, the times when the aircraft was close to the Cabauw tower.

For 8 May, we clearly model higher nitrate concentrations than observed. This discrepancy can be explained by the fact that the model is based on $\mathrm{PM}_{10}$ observations (MARGA), while the aircraft observations (AMS) are $\mathrm{PM}_{0.7}$. Apart from this expected overestimation, we can conclude that the simulation with short (20s) partitioning timescale represents the vertical profile best, with highest concentrations around $1200 \mathrm{~m}$ altitude. The fact that this short-timescale simulation performs best can partly be explained by the fact that the aircraft AMS measures the finest particles, which are equilibrated quickly. The spread of the observations is quite large, which may partly be explained by different aerosol nitrate concentrations in updrafts and downdrafts due to the vertical gradient. This explanation requires further investigation, e.g. with large-eddy simulation.

For 21 May, both the model and the observations show similar nitrate concentrations at $500 \mathrm{~m}$ altitude and at 1200 or $1300 \mathrm{~m}$ altitude. Still, the observed aerosol nitrate concentration at the surface (AMS) is remarkably low, almost $1 \mu \mathrm{g} \mathrm{N} \mathrm{m}^{-3}$ lower than expected from the aircraft observations. If total nitrate was well-mixed through the boundary layer, at least that amount of nitrate should be present in the gas phase at the surface. The MARGAobservations, however, show much lower nitric acid concentrations $\left(<0.2 \mu \mathrm{g} \mathrm{N} \mathrm{m}^{-3}\right)$, so just the transition from gas phase to aerosol phase can not explain the entire difference 

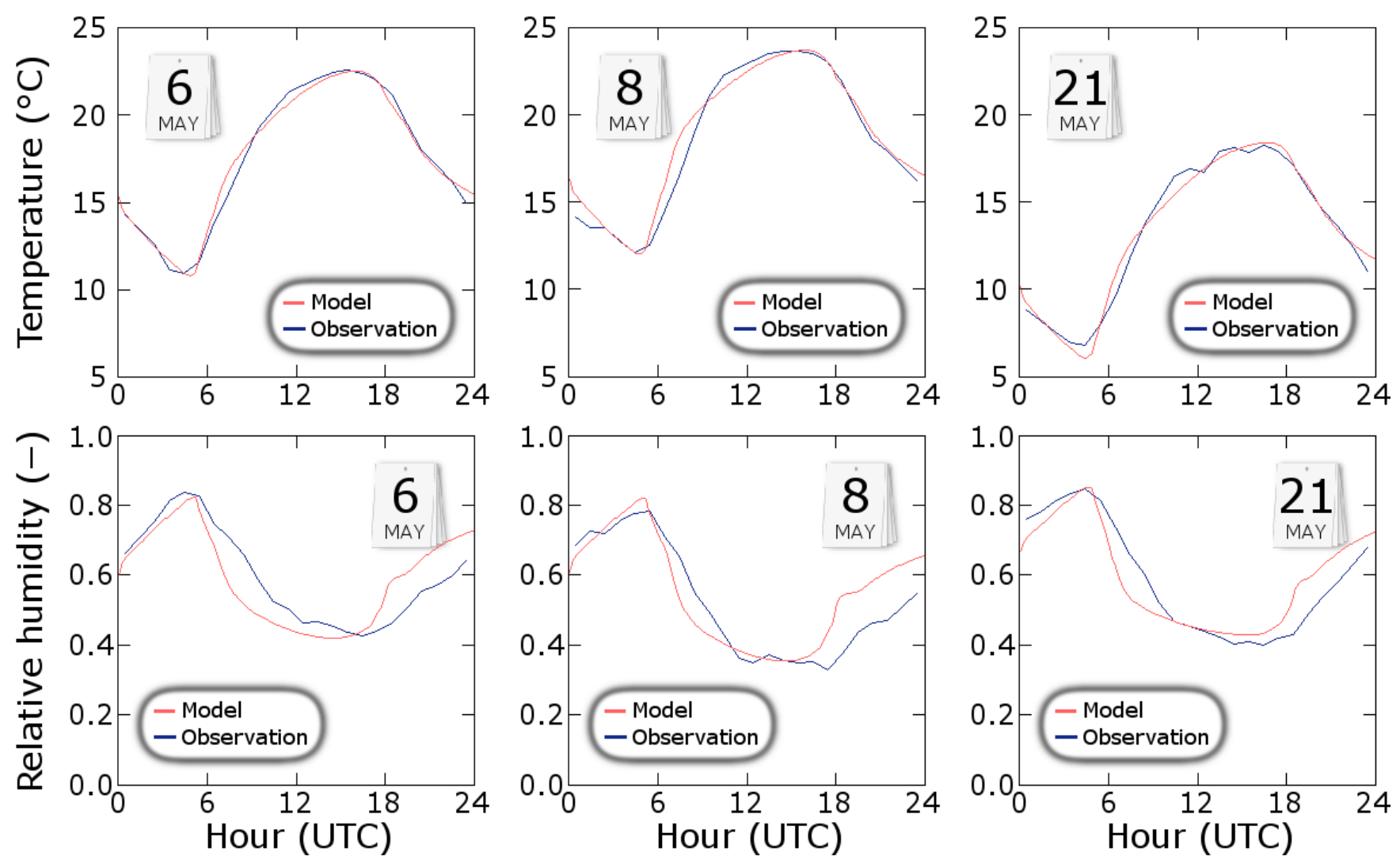

Fig. 3. Upper panels: observed and modelled surface temperature for 6 May (left), 8 May (middle) and 21 May (right). Lower panel: observed and modelled relative humidity for these days.
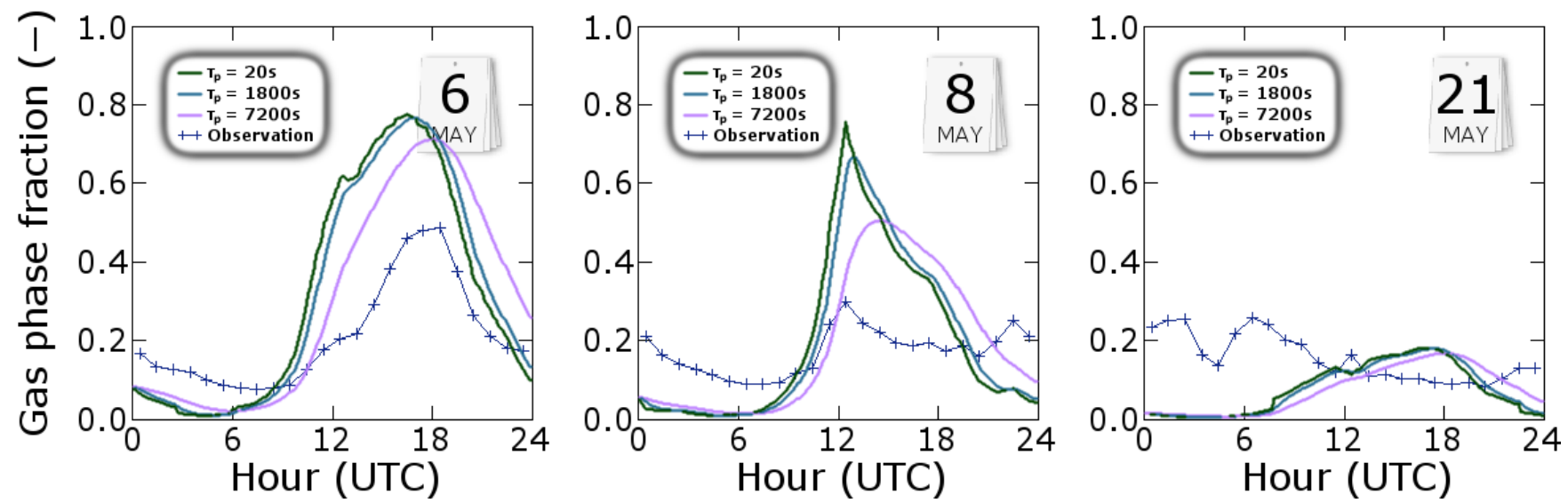

Fig. 4. Partitioning of nitrate, modelled by nudging the equilibrium calculated by ISORROPIA with different timescales, and observation, for 6, 8 and 21 May.

between the surface AMS and the airborne AMS. Coarsemode aerosols, which are not measured by the AMS, or surface processes affecting the fine mode aerosol (see also $\mathrm{Ne}$ mitz et al., 2009), are possible explanations. See also Mensah et al. (2011) for a comparison between MARGA and AMS data.

\subsubsection{Optical analysis}

We calculated the scattering coefficients according to Sect. 2.2.3 and compared them with the scattering coefficients measured by Morgan et al. (2010). The SMPS data required for the optical calculations were only available for 

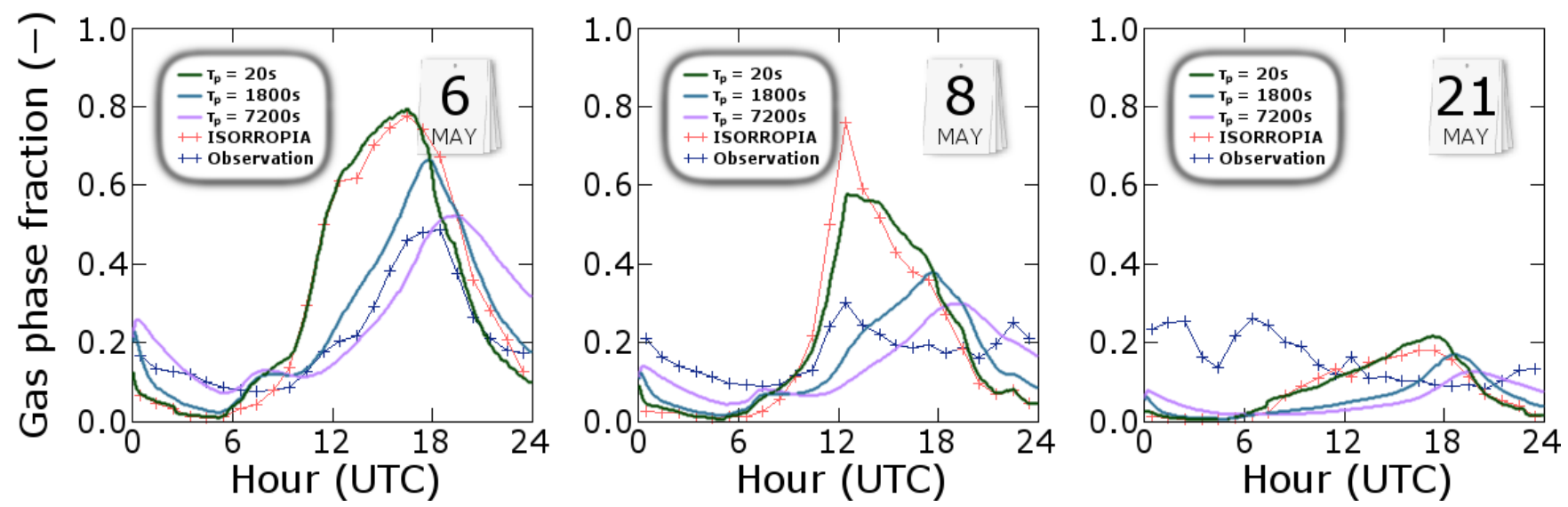

Fig. 5. Partitioning of nitrate modelled by the column model with different timescales of partitioning $\left(\tau_{\mathrm{p}}\right)$, the ISORROPIA-only simulation and the observation for 6 May (left), 8 May (middle) and 21 May (right).

the second half of May 2008, so for 6 and 8 May, we used the SMPS data from 21 May. We will analyse the sensitivity of the optical properties to the aerosol size distribution in Sect. 3.3. Figure 8 shows the modelled scattering profiles for the three selected days. Of each simulation, a plume of three profiles from afternoon hours is shown. The thick $f(\mathrm{RH})$ line is obtained by taking a fixed mixing ratio of aerosol components representative for the lower boundary layer and assuming instant equilibrium for aerosol water. Repartitioning of ammonium nitrate is not taken into account in this latter calculation. Generally, $f(\mathrm{RH})$ rises with altitude. Thus, the effect of additional moisture by rising relative humidity with altitude outweighs the effect of lower aerosol volume concentrations due to lower air density (note that in a well-mixed boundary layer, the mixing ratio is constant with height, not the concentrations).

The observations presented in Fig. 9 of Morgan et al. (2010) are projected on the graphs of 8 and 21 May. The $f(\mathrm{RH})$ profiles of Morgan et al. (2010) are obtained in a similar way as the modelled one. It is based on the measured scattering coefficient at the surface at Cabauw and the observed relative humidity. The effect of additional moisture on aerosols is parameterised as Eq. (1) (see Sect. 2.1). This equation is solved as follows.

$\sigma_{z}=\sigma_{0} \frac{1+a \mathrm{RH}_{z}^{b}}{1+a \mathrm{RH}_{0}^{b}}$

Here, $\sigma_{z}$ is the scattering coefficient at altitude $z, \sigma_{0}$ is the measured scattering coefficient at the surface, $\mathrm{RH}_{z}$ and $\mathrm{RH}_{0}$ are the relative humidities at altitude $z$ and surface. Coefficients $a$ and $b$ are obtained by measurements in the aircraft (see Sect. 2.1). As with the modelled $f(\mathrm{RH})$, the effect of additional moisture on aerosols is also partially compensated by the lower aerosol concentrations due to lower air density.

Like for aerosol nitrate concentrations, our model calculates increasing scattering coefficients with altitude when the partitioning timescale is assumed short. These gradients are stronger on 6 May (almost a doubling of the scattering coefficient over the boundary layer) and weaker on 21 May (no gradient). On 8 May, the situation is in between, with a scattering coefficient increment of $50 \%$ over the boundary layer for short $(20 \mathrm{~s})$ partitioning timescale. Longer partitioning timescales result in small gradients in the scattering coefficient (at most $20 \%$ increase on 6 May with $\tau_{\mathrm{p}}=1800 \mathrm{~s}$ ).

On 6 and 8 May we model a stronger gradient in the scattering coefficient than $f(\mathrm{RH})$ when the timescale of partitioning is not too long. For 21 May, we model a strongly rising $f(\mathrm{RH})$ due to the high relative humidity in the upper boundary layer. The differences between $f(\mathrm{RH})$ and the modelled scattering profiles is mostly due to disequilibrium of aerosol water, as repartitioning of nitrate plays only a small role on this day (see Sect. 3.2.3).

For both 8 and 21 May, our model underestimates the scattering coefficient by about a factor of two. An important issue is that the model only takes secondary inorganic aerosols into account. The lack of organic aerosols in the model can cause quite an underestimation of the scattering coefficient, because organic aerosols are a major component of particulate matter in Europe (Putaud et al., 2004). For 8 May, increasing scattering coefficients with altitude have been observed. Such a gradient is only reproduced by the simulation in which the partitioning timescale is set to $20 \mathrm{~s}$. Like the observed aerosol nitrate concentrations, the observed scattering coefficients on 8 May exhibit large variability, which can be due to differences between convective updrafts and downdrafts as discussed in Sect. 3.2.3. For 21 May, Morgan et al. (2010) do observe a clear gradient in the scattering coefficient, much stronger than $f(\mathrm{RH})$ (red in Fig. 8). The observed aerosol nitrate profile from the AMS, however, does not show such a gradient (see Fig. 7). This suggests that the gradient in the scattering profiles is not due to additional aerosol ammonium nitrate. Possibly, the gradient in the 

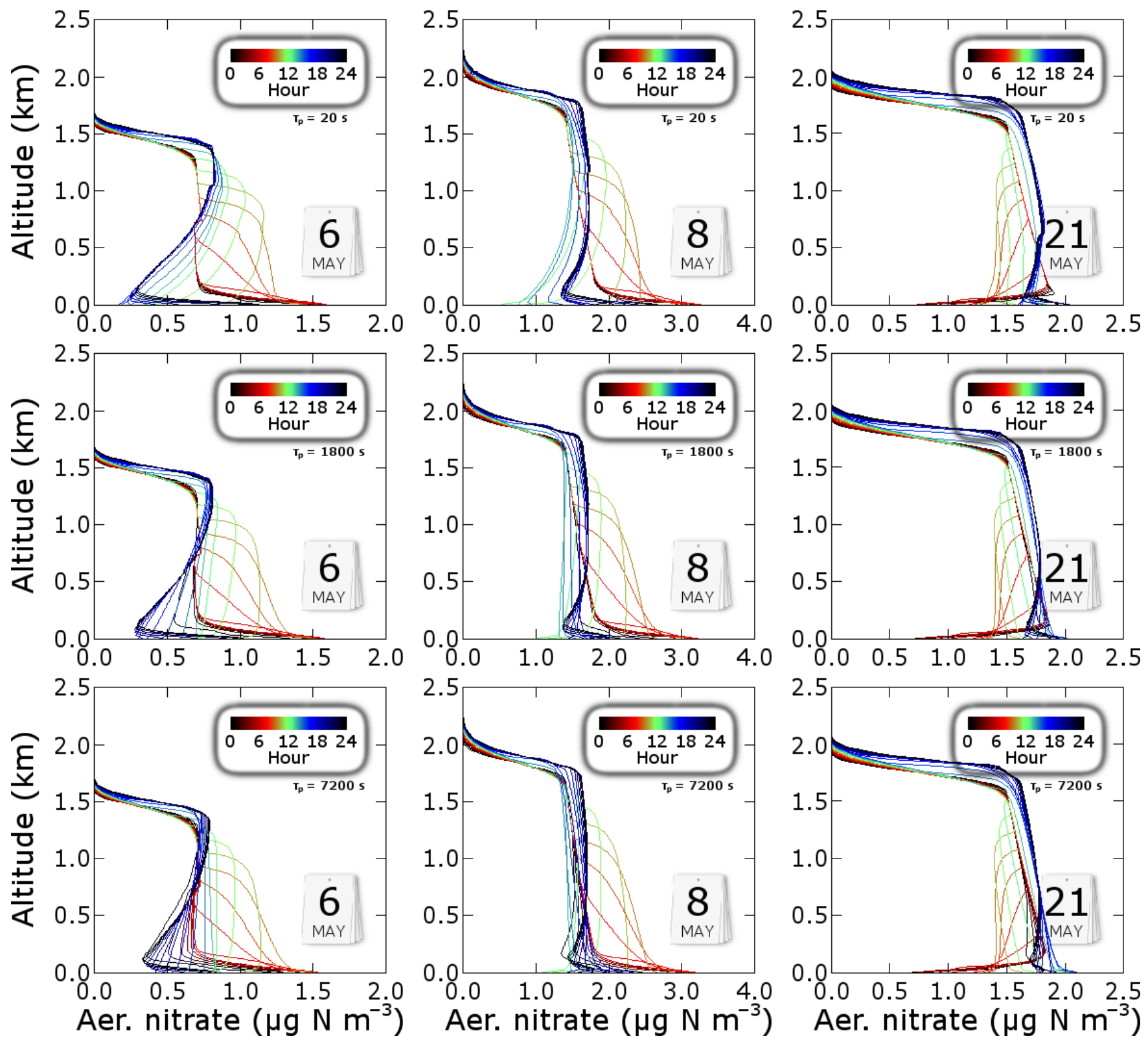

Fig. 6. Modelled aerosol nitrate profiles with partitioning timescales of $20 \mathrm{~s}$ (top panels), $1800 \mathrm{~s}$ (middle panels) and $7200 \mathrm{~s}$ (bottom panels), for 6 May (left), 8 May (middle) and 21 May (right). Each panel contains twenty-four profiles, one per hour, and the colour indicates the time.

observed scattering coefficient is due to organic aerosol components that are more volatile than ammonium nitrate. Our model, lacking these organic components, evidently does not calculate a gradient in the scattering coefficient.

At high relative humidities, the aerosol water uptake becomes extra sensitive to small changes in the relative humidity. This causes the aerosol water uptake and therefore the calculated scattering coefficient to reach very high values at relative humidities above $90 \%$. This is the case in our simulation of 21 May, above $1.5 \mathrm{~km}$ altitude. For $\tau_{\mathrm{p}}=20 \mathrm{~s}$ and for $f(\mathrm{RH})$, we calculate a very sudden increasee in the scattering coefficients to a value more than three times as high as at the surface. The simulations with higher $\tau_{\mathrm{p}}$ do not reach those high values yet in the afternoon because the model also slows down aerosol water uptake with that time constant. However, the high- $\tau_{\mathrm{p}}$ simulations also show high scattering coefficients later in the day when the convective boundary layer collapses (not shown). The observations also do not show such a sudden increase in the scattering coefficients, indicating that that the very sensitive regime was not reached at the time of the observations. 

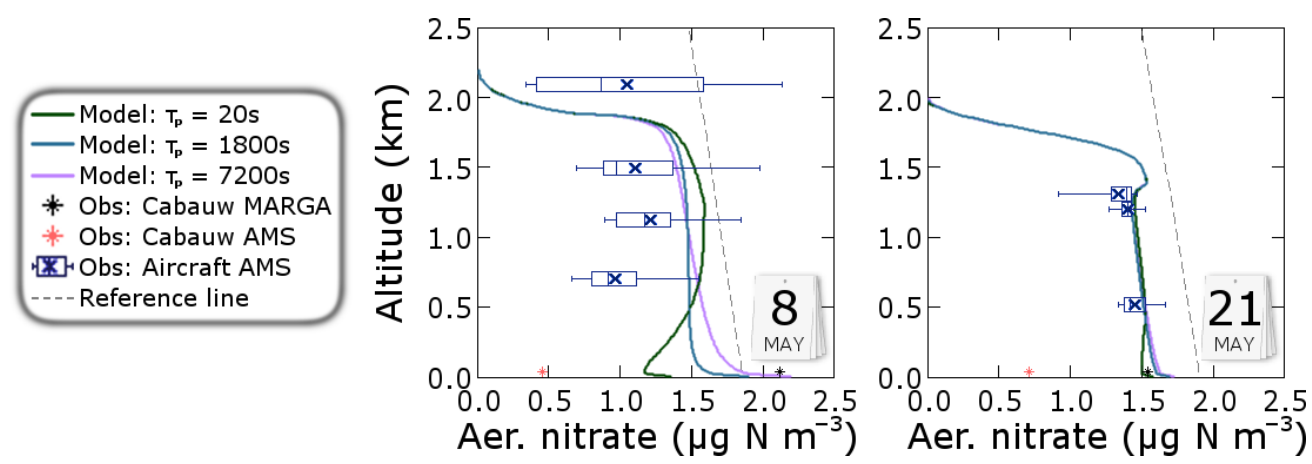

Fig. 7. Modelled aerosol nitrate profiles with partitioning timescales of $20 \mathrm{~s}, 1800 \mathrm{~s}$ and $7200 \mathrm{~s}$, at 15:30 UTC for 8 May and at 11:30 UTC for 21 May. Airbrone aerosol nitrate concentrations measured with the aerosol mass spectrometer, surface aerosol nitrate concentration measured with the aerosol mass spectrometer at Cabauw, and $\mathrm{PM}_{10}$ observations by the MARGA instrument at Cabauw. The reference line shows a scaled concentration of $2.0 \mu \mathrm{g} \mathrm{N} \mathrm{sm}^{-3}$ (scaled to standard temperature and pressure).
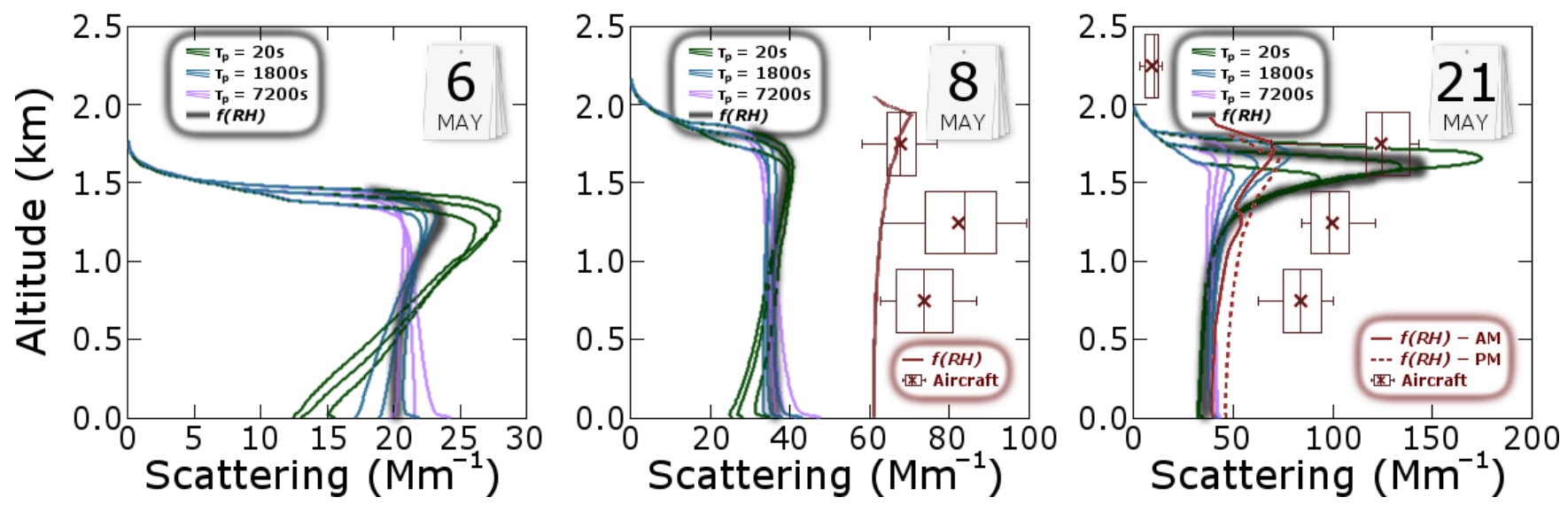

Fig. 8. Modelled scattering profiles for 6 May (left), 8 May (middle) and 21 May (right) at $550 \mathrm{~nm}$ wavelength. Simulations with different partitioning timescales are shown in different colours. For each simulation the profiles of 13:30 UTC, 14:30 UTC and 15:30 UTC are shown. The $f(\mathrm{RH})$ line shows the profile without repartitioning of ammonium nitrate (constant mixing ratios), with instant equilibrium for aerosol water, at 14:30 UTC. For 8 and 21 May, data from Morgan et al. (2010) is shown in red (550 nm wavelength), consisting of aircraft observations and $f(\mathrm{RH})$, which is based on observed scattering coefficient at the surface and observed relative humidity with an assumed power-law relationship between relative humidity and scattering coefficient.

\subsection{Sensitivity of optical properties}

In this section, we present a more technical analysis on how the optical properties of the aerosol vary with the aerosol size distribution, the aerosol composition, and the assumption on how condensed matter is distributed $\left(\sim D^{2}\right.$ or $\left.\sim D^{3}\right)$. We calculate the optical properties with fixed concentrations of aerosol components in equilibrium with air with varying relative humidity $(f(\mathrm{RH}))$. Like in the $f(\mathrm{RH})$ case in Sect. 3.2.4, we do not allow for repartitioning of ammonium nitrate, only the equilibrium for water is calculated. We will compare the calculated $f(\mathrm{RH})$ with observed function fits. First, we rewrite Eq. (1) (see Sect. 2.1).

$\frac{\sigma}{\sigma_{\mathrm{dry}}}-1=a \mathrm{RH}^{b}$
The left hand side of Eq. (14) is the relative gain in scattering coefficient. The right hand side of Eq. (14) is the function fit with parameters $a$ and $b$. Note that these $a$ and $b$ values depend on the type of aerosol measured. The function fit is a straight line on a log-log plot with slope $b$ and value $a$ at $100 \%$ relative humidity $(\mathrm{RH}=1)$. By plotting the relative gain in scattering coefficient (left hand side) on a log-log scale, we can evaluate if our optical calculations result in a similar relationship between scattering coefficient and relative humidity.

Out of the three selected days, valid data of the aerosol size distribution is only available for 21 May. We will therefore evaluate the modelled $f(\mathrm{RH})$ during this day. Measurements of $f(\mathrm{RH})$ are available for several flights in May 2008, including 21 May. Figure 9 displays the comparison between modelled and observed $f(\mathrm{RH})$. The highlighted lines 


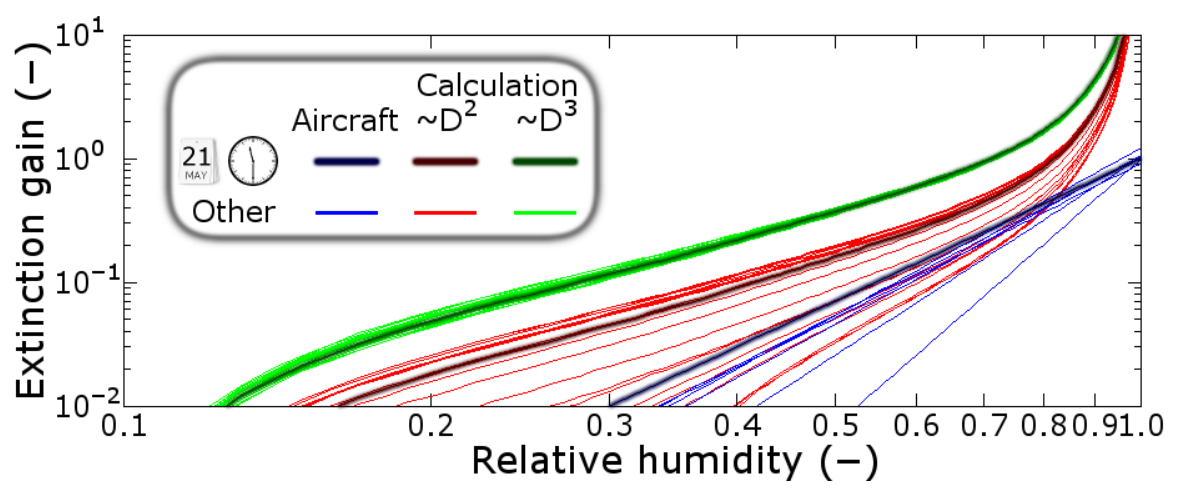

Fig. 9. Relative gain in scattering coefficient of aerosols as a function of relative humidity, without repartitioning of ammonium nitrate, with instant equilibrium for aerosol water. The calculations use observed (MARGA) surface concentrations of ammonium nitrate and ammonium sulphate and SMPS-observations at Cabauw of the aerosol size distribution, both for 21 May. One plume assumes condensation $\left(\sim D^{2}\right)$ and the other assumes condensation $\left(\sim D^{3}\right)$. Both plumes consist of twenty-four calculations, one per hour. The aircraft plots are power-law fits of measurements during several flights. Highlighted are the calculations for 11:30 UTC and the function fit during the flight of 21 May, which was around the same time.

in Fig. 9 correspond to the same time, 21 May around 11:30 UTC. For the majority of the RH-domain, we calculate a power-law relationship between the scattering gain and the relative humidity, indicated by the straight lines. If we analyse these straight parts, we can assign an $a$ and $b$-value to each of the calculations. At high relative humidities, however, the calculations give higher scattering gains. This issue was also discussed in Sect. 3.2.4 (see also Fig. 8). The value $a$ is a multiplication factor of the RH-dependent part of $f(\mathrm{RH})$. Thus, a high (low) value for $a$ indicates that the optical properties of the aerosol are more (less) sensitive to the relative humidity. The value $b$ is the power of the relative humidity, which reduces the scattering gain especially at moderate relative humidities. Thus, a high (low) value for $b$ indicates a reduced (increased) scattering coefficient at moderate humidities compared to low or high humidities.

Remarkable is that the aircraft measurements show very little variability in their $a$-values ( $a=1.033 \pm 0.085)$, while the $b$-values vary considerably $(b=4.812 \pm 1.049)$. The calculations assuming condensation $\left(\sim D^{2}\right)$ also give $a$-values very close to $1.0(a=1.046 \pm 0.087)$ and strong variations in $b$-values, although the calculated $b$-values are significantly lower on average $(b=3.167 \pm 0.928)$. The calculations assuming condensation $\left(\sim D^{3}\right)$ differ more from the observations. The $a$-values are too high $(a=1.979 \pm 0.058)$. The $b$-values of the $\left(\sim D^{3}\right)$ simulation are all similar to the lowest (i.e. worst) $b$-values of the $\left(\sim D^{2}\right)$ simulation, resulting in a low average and a very small spread $(b=2.318 \pm 0.048)$. To compare, the lowest $b$-value for the $\sim D^{2}$-simulation is 2.356. This analysis suggests that the $\left(\sim D^{2}\right)$ assumption performs better than the $\left(\sim D^{3}\right)$ assumption, which is an indication that the gas-aerosol system is generally in disequilibrium (see discussion in Sect. 2.2.3).
High values of $b$ are associated with a higher ammonium nitrate content with respect to ammonium sulphate, which is in line with Tang (1996). On 21 May, however, the ratio between ammonium nitrate and ammonium sulphate did not vary much. High values of $b$ are also associated with an aerosol size distribution dominated by fine particles. Differences in the aerosol size distribution are responsible for the variations in $b$ for the $\left(\sim D^{2}\right)$ calculations. In the $\left(\sim D^{3}\right)$ calculations, where condensation on coarse aerosols is favoured, the $b$-values are small. The observations show higher $b$ values than the calculations, which can mean two things. One possibility is that the real aerosols take up more water than the modelled aerosols. As discussed in Morgan et al. (2010) and in this work, aircraft observations show elevated nitrate to sulphate ratios compared to the surface, on which the calculations of Fig. 9 are based. This is associated with higher $b$-values. Moreover, semi-volatile organic aerosols might also result in higher $b$-values. Organic compounds have strongly varying hygroscopic properties (Varutbangkul et al., 2006), so organic compounds could in theory also be responsible for the high observed $b$-values. The second possibility is that the assumption of homogeneous spherical aerosols causes a bias, an issue that will not be explored here.

\subsection{Correcting the instant equilibrium}

In Sects. 3.1 and 3.2.2 we showed that assuming instant gasaerosol equilibrium may result in biases in the surface nitrate partitioning (already shown in Schaap et al., 2011). Most coarse-resolution models, however, do not benefit from a delay time as used in this study, because it is required that turbulent mixing is resolved by the model. We will therefore present a practical modification of the instant-equilibrium assumption by using ISORROPIA with the temperature and 

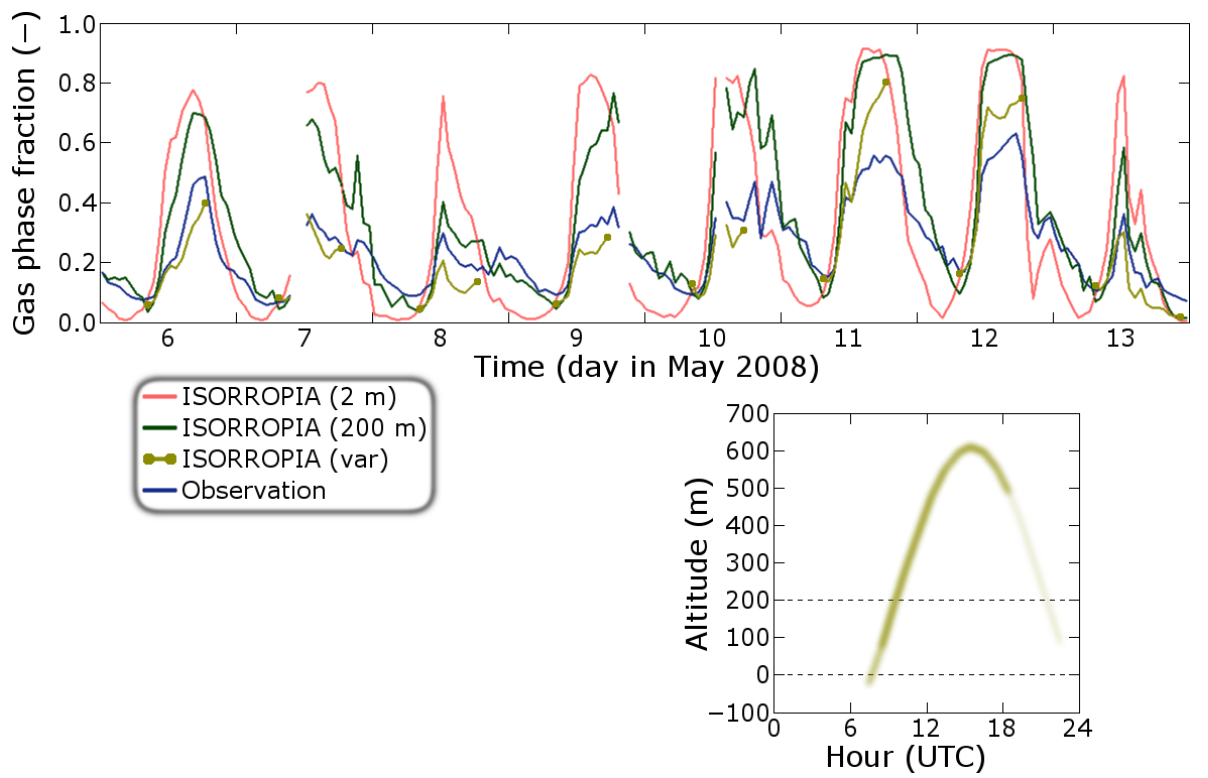

Fig. 10. Upper panel: calculated equilibrium gas phase fraction of nitrate using observations of total ammonium, total nitrate and sulphate, using temperature and relative humidity at $2 \mathrm{~m}$, at $200 \mathrm{~m}$, and at varying altitude (only for unstable conditions), and observed gas phase fraction of nitrate, in the period 6-13 May 2008. Lower panel: altitude as function of time of the day used for the varying-altitude calculation. The thickness of the line represents the number of days at which the conditions were unstable at that time.

relative humidity at a higher altitude rather than at the surface.

We repeated the instant-equilibrium calculations for the fair-weather period (6-13 May) with observations of temperature and relative humidity at $200 \mathrm{~m}$ altitude (highest observation in the Cabauw tower). As shown in Fig. 10 (upper panel, green line), we see that the results improve significantly during the nights. In daytime, the difference between the 200-m meteo and the 2-m meteo is very small, indicating that the altitude of $200 \mathrm{~m}$ is still too low during daytime.

Because no observations are available at altitudes above $200 \mathrm{~m}$, we obtained the temperature and humidity at higher altitudes by transforming the observations at $200 \mathrm{~m}$ assuming constant specific humidity and potential temperature. These assumptions are only valid in a well-mixed boundary layer. We will therefore only use this transformation at unstable conditions $\left(T_{2} \mathrm{~m}>T_{200 \mathrm{~m}}\right)$. We prescribed an altitude as function of the time in the day with three fit parameters. We calculated the equilibrium of the gas-aerosol system using the meteorological data at that altitude (using the transformation from the 200-m observation), only at unstable conditions in the period from 6-13 May. We determine the fit parameters such that the error in the calculated gas-aerosol equilibrium is smallest. The fit function that is used looks like:

$h=a+b \cdot \sin \left(2 \pi\left(\frac{t}{24 \mathrm{~h}}-c\right)\right)$

Here, $t$ is the time, $h$ is the altitude and $\{a, b, c\}$ are fit parameters that are tuned to $a=190.1 \mathrm{~m}, b=418.5 \mathrm{~m}$ and $c=0.398$. The height function is displayed in the lower panel of Fig. 10 and the gas-aerosol equilibrium with this height function is shown in upper panel of Fig. 10 in dark yellow. Note again that periods with stable conditions are skipped.

This analysis shows that, at least for clear days in May, biases in the surface nitrate partitioning can be substantially decreased by calculating the equilibrium using temperature and humidity at a higher altitude rather than at the surface. The altitude at which the temperature and humidity should be sampled can be described with a simple function with only three parameters (Eq. 15).

\section{Conclusions}

An explanatory model study has been carried out to investigate the partitioning of ammonium nitrate aerosols in the convective boundary layer on clear days in May 2008. On clear summer days, the equilibrium model ISORROPIA show a clear diurnal cycle in the equilibrium of ammonium nitrate, with a maximum gas phase fraction during daytime and a maximum aerosol phase fraction during night-time. This diurnal cycle in the calculated equilibrium, however, is stronger than the diurnal cycle in the partitioning observed with the MARGA-instrument at Cabauw. Our hypothesis is that the gas-aerosol equilibrium is never fully established in reality.

When introducing a finite speed at which gas-aerosol equilibrium is established, the modelled partitioning is closer to 
the observations than when assuming instant equilibrium. The diurnal cycle in the gas-aerosol partitioning at the surface is delayed, weakened and on average shifted towards the aerosol phase due to mixing with air from the upper boundary layer. The observed gas-aerosol partitioning at the surface is best reproduced with a long partitioning timescale (two hours). Coarse-resolution models can account for the delayed gas-aerosol equilibrium by calculating the surface gas-aerosol partitioning using the temperature and relative humidity at a higher altitude. For clear days in May 2008, this altitude is close to $200 \mathrm{~m}$ in the night and up to $600 \mathrm{~m}$ on daytime.

In the upper boundary layer, ammonium nitrate shifts to the aerosol phase because of lower temperatures and higher relative humidities. This creates a gradient of aerosol nitrate concentration in the convective boundary layer even though the layer is well-mixed. When the timescale of gas-aerosol equilibrium is long, the gradient is small. Our model shows aerosol nitrate gradients comparable to Morgan et al. (2010) when partitioning is assumed quick (less than a half an hour). Quantitative comparison is difficult because the measurements of Morgan et al. (2010) consist of the fine fraction $\left(\mathrm{PM}_{0.7}\right)$, while our model models $\mathrm{PM}_{10}$.

The calculated scattering coefficient shows gradients with altitude similar to those of aerosol nitrate. Our model underestimates the scattering coefficient by about a factor of two due to the lack of organic aerosols in our model. Morgan et al. (2010) measured organic aerosol with the AMS and concluded that its contribution to the total aerosol mass is large in line with Putaud et al. (2004). Sensitivity studies point out that the optical properties depend on the aerosol size distribution, the aerosol composition and on how the model assumes the distribution of condensed matter. As explained in Tang (1996), the hygroscopic growth on ammonium nitrate aerosols is more sensitive to the relative humidity than that of ammonium sulphate aerosols. With our optical analysis, we also found indirect evidence that for situations similar to the days simulated in this article, assuming condensation proportional to aerosol surface $\left(\sim D^{2}\right)$ is more realistic than assuming condensation proportional to aerosol volume $\left(\sim D^{3}\right)$.

The situation at the surface $\left(\mathrm{PM}_{10}\right)$ is simulated best with a long partitioning timescale while the vertical profiles $\left(\mathrm{PM}_{0.7}\right)$ are modelled best with a short partitioning timescale. This issue should be investigated with a size-resolved aerosol approach (e.g. M7; Vignati et al., 2004). The size-dependence of the equilibration time (Meng and Seinfeld, 1996) can be implemented in more detail than in the bulk approach described here.

Acknowledgements. Airborne data was obtained using the BAe146-310 large Atmospheric Resesearch Aircraft (ARA) flown by Directflight Ltd and managed by the Facility for Airborne Atmospheric Measurements (FAAM), which is a joint facility of the Natural Environment Research Council (NERC) and the Met Office. We acknowledge Astrid Kiendler-Scharr and Amewu
Mensah for providing ground-based AMS data. We would like to thank Geert-Jan Roelofs for sharing his knowledge about aerosol microphysics. This work is supported by the EU FP7 IP PEGASOS (FP7-ENV-2010/265148).

Edited by: N. Riemer

\section{References}

Anderson, T. L., Covert, D. S., Marshall, S. F., Laucks, M. L., Charlson, R. J., Waggoner, A. P., Ogren, J. A., Caldow, R., Holm, R. L., Quant, F. R., Sem, G. J., Wiedensohler, A., Ahlquist, N. A., and Bates, T. S.: Performance characteristics of a high-sensitivity, three-wavelength, total scatter/backscatter nephelometer, J. Atmos. Ocean. Tech., 13, 967986, doi:10.1175/1520-0426(1996)013<0967:PCOAHS > 2.0;2, 1996.

Aspnes, D. E., Theeten, J. B., and Hottier, F.: Investigation of effective-medium models of microscopic surface roughness by spectroscopic ellipsometry, Phys. Rev. B., 20, 3292-3302, doi:10.1103/PhysRevB.20.3292, 1979.

Bruggeman, D. A. G.: Berechnung verscheidener physikalischer Konstanten von heterogenen Substanzen, 1. Dielektrizitätskonstanten und Leitfähigkeiten der Mischkörper aus isotropen Substanzen, Ann. Phys., 416, 636-664, doi:10.1002/andp.19354160802, 1935.

Canagaratna, M. R., Jayne, J. T., Jimenez, J. L., Allan, J. D., Alfarra, M. R., Zhang, Q., Qnasch, T. B., Drewnick, F., Coe, H., Middlebrook, A., Delia, A. E., Williams, L. R., Trimborn, A. M., Northway, M. J., DeCarlo, P. .F., Kolb, C. E., Devidovits, P., and Worsnop, D. R.: Chemical and microphysical characterization of ambient aerosols with the aerodyne aerosol mass spectrometer, Mass Spectrom. Rev., 26, 185-222, doi:10.1002/mas.20115, 2007.

Capaldo, K. P., Pilinis C., and Pandis, S. N.: A computationally efficient hybrid approach for dynamic gas/aerosol transfer in air quality models, Atmos. Environ., 34, 3617-3627, doi:10.1016/S1352-2310(00)00092-3, 2000.

Cheng, Y. H. and Tsai, C. J.: Evaporation loss of ammonium nitrate particles during filter sampling, J. Aerosol Sci., 28, 1553-1567, doi:10.1016/S0021-8502(97)00033-5, 1997.

DeCarlo, P. F., Slowik, J. G., Worsnop, D. R., Davidovits, P., and Jimenez, J. L.:Particle morphology and density characterization by combined mobility and aerodynamic diameter measurements. Part 1: Theory, Aerosol Sci. Technol., 38, 1185-1205, doi:10.1080/027868290903907, 2004.

Drewnick, F., Hings, S. S., DeCarlo, P. F., Jayne, J. T., Gonin, M., Fuhrer, K., Weimer, S., Jimenez, J. L., Demerjian, K. L., Borrmann, S., Worsnop, and D. R.: A new time-of-flight aerosol mass spectrometer (TOF-AMS) - Instrument description and first field deployment, Aerosol Sci. Technol., 39, 637-658, doi:10.1080/02786820500182040, 2005.

Feng, Y. and Penner, J. E.: Global modeling of nitrate and ammonium: Interaction of aerosols and tropospheric chemistry, J. Geophys. Res., 112, D01304, doi:10.1029/2005JD006404, 2007.

Fisseha, R., Dommen, J., Gutzwiller, L., Weingartner, E., Gysel, M., Emmenegger, C., Kalberer, M., and Baltensperger, U.: Seasonal and diurnal characteristics of water soluble inorganic 
compounds in the gas and aerosol phase in the Zurich area, Atmos. Chem. Phys., 6, 1895-1904, doi:10.5194/acp-6-1895-2006, 2006.

Fountoukis, C. and Nenes, A.: ISORROPIA II: a computationally efficient thermodynamic equilibrium model for $\mathrm{K}^{+}$ $\mathrm{Ca}^{2+}-\mathrm{Mg}^{2+}-\mathrm{NH}_{4}^{+}-\mathrm{Na}^{+}-\mathrm{SO}_{4}^{2-}-\mathrm{NO}_{3}^{-}-\mathrm{Cl}^{-}-\mathrm{H}_{2} \mathrm{O}$ aerosols, Atmos. Chem. Phys., 7, 4639-4659, doi:10.5194/acp-7-4639-2007, 2007.

von Glasgow, R.: Pollution meets sea salt, Nat. Geosci., 1, 292-293, doi:10.1038/ngeo192, 2008.

Haywood, J. and Boucher, O.: Estimates of the direct and indirect radiative forcings due to tropospheric aerosols: a review, Rev. Geophys., 38, 513-543, doi:10.1029/1999RG000078, 2000.

Hecht, E.: Optics, Fourth edition, Addison-Wesley Publishing Co., Reading, Pennsylvania, 2003.

Hess, M., Koepke, P., and Schult, I.: Optical Properties of Aerosols and Clouds: The Software Package OPAC, B. Am. Meteorol. Soc., 79, 831-844, doi:10.1175/15200477(1998)079<0831:OPOAAC > 2.0.CO;2, 1998.

Hong, S.-Y. and Pan, H.-L.: Nonlocal boundary layer vertical diffusion in a Medium-Range Forecast model, Mon. Weather Rev., 124, 2322-2339, doi:0.117515200493(1996)124<2322:NBLVDI> 2.0.CO;2, 1996.

Intergovernmental Panel on Climate Change, edited by: Solomon, S., Qin, D., Manning, M., Chen, Z., Marquis, M., Averyt, K. B., Tignor, M., and Miller, H. L.: Climate change 2007: The physical Science Basis, IPCC Fourth Assassement report (AR4), 2007.

Jarvis, P. G.: The interpretation of the variations in leaf water potentials and stomatal conductance found in canopies in the field, Philos. Trans. R. Soc. Lond. B273, 593-610, doi:10.1098/rstb.1976.0035, 1976.

Kaufman, Y. J., Tanré, D., and Boucher, O.: A satellite view of aerosols in the climate system, Nature, 419, 215-223, doi:10.1038/nature01091, 2002.

Keuken, M. P., Schoonebeek, C. A. M., Vanwensveenlouter, A., and Slanina, J.: Simultaneous Sampling of $\mathrm{NH}_{3}, \mathrm{HNO}_{3}, \mathrm{HCl}$, $\mathrm{SO}_{2}$ and $\mathrm{H}_{2} \mathrm{O}_{2}$ in Ambient Air by a Wet Annular Denuder System, Atmos. Environ., 22, 2541-2548, doi:10.1016/00046981(88)90486-6, 1988.

Khlystov, A., Wyers, G. P., and Slanina, J.: The Steam-Jet Aerosol Collector, Atmos. Environ., 29, 2229-2234, doi:10.1016/13522310(95)00180-7, 1995.

Kulmala, M., Asmi, A., Lappalainen, H. K., Carslaw, K. S., Pöschl, U., Baltensperger, U., Hov, Ø., Brenquier, J.-L., Pandis, S. N., Facchini, M. C., Hansson, H.-C., Wiedensohler, A., and O'Dowd, C. D.: Introduction: European Integrated Project on Aerosol Cloud Climate and Air Quality interactions (EUCAARI) - integrating aerosol research from nano to global scales, Atmos. Chem. Phys., 9, 2825-2841, doi:10.5194/acp-9-2825-2009, 2009.

Madronich, S.: Photodissociation in the atmosphere. 1. Actinic flux and the effect of ground reflections and clouds, J. Geophys. Res., 92, 9740-9752, doi:10.1029/JD092iD08p09740, 1987.

Meng, Z. and Seinfeld, J. H.: Time scales to achieve atmospheric gas-aerosol equilibrium for volatile species, Atmos. Environ., 30, 2889-2900, doi:10.1016/1352-2310(95)00493-9, 1996.

Mensah, A. A., Holzinger, R., Otjes, R., Trimborn, A., Mentel, T. F., ten Brink, H., Henzing, B., and Kiendler-Scharr, A.: Aerosol chemical composition at Cabauw, the Netherlands as observed in two intensive periods in May 2008 and March 2009, Atmos. Chem. Phys. Discuss., 11, 27661-27699, doi:10.5194/acpd-1127661-2011, 2011.

Metzger, S., Dentener, F., Krol, M., Jeuken, A., and Lelieveld, J.: Gas/aerosol partitioning 2: Global modeling results, J. Geophys. Res., 107, 4313, doi:10.1029/2001JD001103, 2002a.

Metzger, S., Dentener, F., Pandis, S., and Lelieveld, J.: Gas/aerosol partitioning 1: A computationally efficient model, J. Geophys. Res., 107, 4312, doi:10.1029/2001JD001102, 2002 b.

Morgan, W. T., Allan, J. D., Bower, K. N., Esselborn, M., Harris, B., Henzing, J. S., Highwood, E. J., Kiendler-Scharr, A., McMeeking, G. R., Mensah, A. A., Northway, M. J., Osborne, S., Williams, P. I., Krejci, R., and Coe, H.: Enhancement of the aerosol direct radiative effect by semi-volatile aerosol components: airborne measurements in North-Western Europe, Atmos. Chem. Phys., 10, 8151-8171, doi:10.5194/acp-10-8151-2010, 2010.

Morino, Y., Kondo, Y., Takegawa, N., Miyazaki, Y., Kita, K., Komazaki, Y., Fukuda, M., Miyakawa, T., Moteki, N., and Worsnop, D. R.: Partitioning of $\mathrm{HNO}_{3}$ and particulate nitrate over Tokyo: Effect of vertical mixing, J. Geophys. Res., 111, D15215, doi:10.1029/2005JD006887, 2006.

Moya, M., Ansari, A. S., and Pandis, S. N.: Partitioning of nitrate and ammonium between the gas and particulate phases during the 1997 IMADA-AVER study in Mexico City, Atmos. Environ., 35, 1791-1804, doi:10.1016/S1352-2310(00)00292-2, 2001.

Nemitz, E., Phillips, G. J., Thomas, R., Di Marco, C. F., Tang, S., Coe, H., Allan, J., Harrison, R. M., and Fowler, D: Nitrate Dynamics in UK Urban Environments, European Aerosol Conference 2009, Karlsruhe, Germany, 6-11 September 2009, Abstract T130A10, 2009.

Nenes, A., Pandis, S. N., and Pilinis, C.: ISORROPIA: A new thermodynamic equilibrium model for multiphase multicomponent inorganic aerosols, Aquat. Geochem., 4, 123-152, doi:10.1023/A:1009604003981, 1998.

Noh, Y., Chun, W. G., Hong, Y., and Raasch, S.: Improvement of the K-profile model for the planetary boundary layer based on large eddy simulation data, Bound. Lay. Meteorol., 107, 401427, doi:10.1023/A:1022146015946, 2003.

Putaud, J.-P., Raes, F., van Dingenen, R., Brüggemann, E., Facchini, M. C., Decesari, S., Fuzzi, S., Gehrig, R., Hüglin, C., Laj, P., Lorbeer, G., Maenhaut, W., Mihalopoulos, N., Müller, K., Querol, X., Rodriguez, S., Schneider, J., Spindler, G., ten Brink, H., Tørsetb, K., and Wiedensohler, A.: A European aerosols phenomenology-2: chemical characteristics of particulate matter at kerbside, urban, rural and background sites in Europe, Atmos., Environ., 38, 2579-2595, doi:10.1016/j.atmosenv.2004.01.041, 2004.

Rosenfeld, D., Lohmann, U., Raga, G. B., O’Dowd, C. D., Kulmala, M., Fuzzi, S., Reissell, A., and Andreae, M. O.: Flood or Drought: How Do Aerosols Affect Precipitation?, Science, 321, 1309-1313, doi:10.1126/science.1160606, 2008.

Russchenberg, H. W. J., Bosveld, F., Swart, D., ten Brink, H., de Leeuw, G., Uijlenhoet, R., Arbesser-Rastburg, B., van der Marel, H., Ligthart, L., Boers, R., and Apituley, A.: Ground-based atmospheric remote sensing in The Netherlands; European outlook, IEEE T. Commun., 2252-2258, doi:10.1093/ietcom/e88b.6.2252, 2005.

Schaap, M., Müller, K., and ten Brink, H. M.: Constructing the 
European aerosol nitrate concentration Field from quality analysis data, Atmos. Environ., 36, 1323-1335, doi:10.1016/S13522310(01)00556-8, 2002.

Schaap, M., van Loon, M., ten Brnik, H. M., Dentener, F. J., and Builtjes, P. J. H.: Secondary inorganic aerosol simulations for Europe with special attention to nitrate, Atmos. Chem. Phys., 4, 857-874, doi:10.5194/acp-4-857-2004, 2004.

Schaap, M., Otjes, R. P., and Weijers, E. P.: Illustrating the benefit of using hourly monitoring data on secondary inorganic aerosol and its precursors for model evaluation, Atmos. Chem. Phys., 11, 11041-11053, doi:10.5194/acp-11-11041-2011, 2011.

Slanina, J., ten Brink, H. M., Otjes, R. P., Even, A., Jongejan, P., Khlystov, A., Waijers-Ijpelaan, A., and Hu, M.: The continuous analysis of nitrate and ammonium in aerosols by the steam jet aerosol collector (SJAC): extension and validation of the methodology, Atmos. Environ., 35, 2319-2330, doi:10.1016/S13522310(00)00556-2, 2001.

Steeneveld, G. J., van de Wiel, B. J. H., and Holtslag, A. A. M.: Diagnostic equations for the stable boundary layer height: Evaluation and dimensional analysis, J. Appl. Meteorol. Clim., 46, 212-225, doi:10.1175/JAM2454.1, 2007.

Takahama, S., Wittig, A. E., Vayenas, D. V., Davidson, C. I., and Pandis, S. M.: Modeling the diurnal variation of nitrate during the Pittsburgh Air Quality Study, J. Geophys. Res., 109, D16S06, doi:10.1029/2003JD004149, 2004.

Tang, I. N.: Chemical and size effects of hygroscopic aerosols on light scattering coefficients, J. Geophys. Res., 101, 1924519250, doi:10.1029/96JD03003, 1996.

ten Brink, H. M., Plomp, A., Spoelstra, H., and van de Vate, J. F.: A high-resolution electrical mobility aerosol spectrometer (MAS), J. Aerosol Sci., 14, 589-597, doi:10.1016/0021-8502(83)900642, 1983.

ten Brink, H. M., Kruisz, C., Kos, G. P. A., and Berner, A.: Composition/size of the light-scattering aerosol in the Netherlands, Atmos. Environ., 31, 3955-3962, doi:10.1016/S13522310(97)00232-X, 1997.

ten Brink, H., Otjes, R., Jongeman, P., and Kos, G.: Monitoring of the ratio of nitrate to sulphate in size-segregated submicron aerosol in the Netherlands, Atmos. Res., 92, 270-276, doi:10.1016/j.atmosres.2008.12.003, 2009.

Thomas, R. M., Trebs, I., Otjes, R., Jongejan, P. A. C., ten Brink, H., Phillips, G., Kortner, M., Meixner, F. X., and Nemitz, E.: An automated analyzer to measure surface-atmosphere exchange fluxes of water soluble inorganic aerosol compounds and reactive trace gases, Environ. Sci. Technol., 43, 1412-1418, doi:10.1021/es8019403, 2009.

Toon, O. B., Pollack, J. B., and Khare, B. N.: Optical-Constants os Several Atmospheric Aerosol Species - Ammonium-Sulfate, Alluminum-Oxide, And Sodium-Chloride, J. Geophys. Res., 81, 5733-5748, doi:10.1029/JC081i033p05733, 1976.

Trebs, I., Meixner, F. X., Slanina, J., Otjes, R., Jongejan, P., and Andreae, M. O.: Real-time measurements of ammonia, acidic trace gases and water-soluble inorganic aerosol species at a rural site in the Amazon Basin, Atmos. Chem. Phys., 4, 967-987, doi:10.5194/acp-4-967-2004, 2004.

Troen, I. B. and Mahrt, L.: A simple model of the atmospheric boundary layer; sensitivity to the surface evaporation, Bound. Lay. Meteorol., 37, 129-148, doi:10.1007/BF00122760, 1986.

Varutbangkul, V., Brechtel, F. J., Bahrein, R., Ng, N. L., Keywood,
M. D., Kroll, J. H., Flagan, R. C., Seinfeld, J. H., Lee, A., and Goldstein, A. H.: Hygroscopic of secondary organic aerosols formed by oxidation of cycloalkanes, monoterpenes, sesquiterpenes, and related compounds, Atmos. Chem. Phys., 6, 23672388, doi:10.5194/acp-6-2367-2006, 2006.

Vestreng, V., Myhre, G., Fagerli, H., Reis, S., and Tarrasón, L.: Twenty-five years of continuous sulphur dioxide emission reduction in Europe, Atmos. Chem. Phys., 7, 3663-3681, doi:10.5194/acp-7-3663-2007, 2007.

Vestreng, V., Ntziachristos, L., Semb, A., Reis, S. Isaksen, I. S. A., and Tarrasón, L.: Evolution of $\mathrm{NO}_{\mathrm{x}}$ emissions in Europe with focus on road transport control measures, Atmos. Chem. Phys., 9, 1503-1520, doi:10.5194/acp-9-1503-2009, 2009.

Vignati, E., Wilson, J., and Stier, P.: M7: An efficient size-resolved aerosol microphysics module for large-scale aerosol transport models, J. Geophys. Res., 109, D22202, doi:10.1029/2003JD004485, 2004.

Wang, S. C. and Flagan, R. C.: Scanning electrical mobility spectrometer, Aerosol Sci. Technol., 13, 230-240, doi:10.1080/02786829008959441, 1990.

Wang, J., Hoffmann, A. A., Park, R. J., Jacob, D. J., and Martin, S. T.: Global distribution of solid and aqueous sulfate aerosols: Effect of the hysteresis of particle phase transition, J. Geophys. Res., 103, D11206, doi:10.1029/2007JD009367, 2008.

Weast, R. C.: Handbook of Chemistry and Physics, 66th edn., CRC Press, Florida, USA, 1985.

Weijers, E. P., Schaap, M., Nguyen, L., Matthijsen, J., Denier van der Gon, H. A. C., ten Brink, H. M., and Hoogerbrugge, R.: Anthropogenic and natural constituents in particulate matter in the Netherlands, Atmos. Chem. Phys., 11, 2281-2294, doi:10.5194/acp-11-2281-2011, 2011.

Wexler, A. S. and Seinfeld, J. H.: Analysis of aerosol ammonium nitrate departures from equilibrium during SCAQS, Atmos. Environ., 26A, 579-591, doi:10.1016/0960-1686(92)90171-G, 1992.

Wicker, L. J. and Skamarock, W. C.: Time splitting methods for elastic models using forward time schemes, Mon. Weather Rev., 130, 2088-2097, doi:10.1175/15200493(2002)130<2008:TSMFEM>2.0.CO;2, 2002.

Wiedensohler, A.: An approximation of the bipolar charge distribution for particles in the submicron size range, J. Aerosol Sci., 19, 387-389, doi:10.1016/0021-8502(88)90278-9, 1988.

Yu, S., Dennis, R., Roselle, S., Nenes, A., Walker, J., Eder, B., Schere, K., Swall, J., and Robarge, W.: An assessment of the ability of three-dimensional air quality models with current thermodynamic equilibrium models to predict aerosol $\mathrm{NO}_{3}^{-}, \mathrm{J}$. Geophys. Res., 10, D07S13, 1-22, doi:10.1029/2004JD004718, 2005.

Yu, X.-Y., Lee, T., Ayres, B., Kreidenweis, S. M., Malm, W., and Collett, J. L. J.: Loss of fine particulate ammonium from denuded nylon filters, Atmos. Environ., 40, 4797-4807, doi:10.1016/j.atmosenv.2006.03.061, 2006.

Zhang, J., Charmeides, W. L., Weber, R., Cass, G., Orsini, D., Edgerton, E., Jongejan, P., and Slanina, J.: An evaluation of the thermodynamic equilibrium assumption for fine particulate composition: Nitrate and ammonium during the 1999 Atlanta Supersite experiment, J. Geophys. Res., 108, 8414, doi:10.1029/2001JD001592, 2003.

Zhang, X. and McMurry, P. H.: Evaporative losses of fine particulate nitrates during sampling, Atmos. Environ., 26A, 3305-3312, 
doi:10.1016/0960-1686(92)90347-N, 1992.

Zieger, P., Weingartner, E., Henzing, J., Moerman, M., de Leeuw, G., Mikkilä, J., Ehn, M., Petäjä, T., Clémer, K., van Roozendael, M., Yilmaz, S., Frieß, U., Irie, H., Wagner, T., Shaiganfar, R., Beirle, S., Apituley, A., Wilson, K., and Baltensperger, U.:
Comparisonof ambient aerosol extinction coefficients obtained from in-situ, MAX-DOAS and LIDAR measurements at Cabauw, Atmos. Chem. Phys., 11, 2603-2624, doi:10.5194/acp11-2603-2011, 2011. 